\title{
Recent Advances in Flame Retardant Bio-Based Benzoxazine Resins
}

\author{
Hongliang Ding, Xin Wang, Lei Song and Yuan Hu
}

State Key Laboratory of Fire Science, University of Science and Technology of China, Hefei, 230026, China

${ }^{*}$ Corresponding Author: Xin Wang. Email: wxcmx@ustc.edu.cn

Received: 12 July 2021 Accepted: 06 August 2021

\begin{abstract}
Benzoxazines have attracted wide attention from academics all over the world because of their unique properties. However, most of the production and preparation of benzoxazine resins depends on petroleum resources now, especially bisphenol A-based benzoxazine. Therefore, owing to the environmental impacts, the development of bio-based benzoxazines is gaining more and more interest to substitute petroleum-based benzoxazines. Similar to petroleum-based benzoxazines, most of bio-based benzoxazines suffer from flammability. Thus, it is necessary to endow bio-based benzoxazines with outstanding flame retardancy. The purpose of this review is to summarize the latest advance in flame retardant bio-based benzoxazines. First, three methods of the synthesis of bio-based benzoxazines are introduced briefly. Furthermore, the curing mechanism of benzoxazine and the effect of branched chains on the curing behavior are also discussed and summarized. Subsequently, this review focuses on fully bio-based benzoxazines, partly bio-based benzoxazines, and bio-based benzoxazine composite materials in terms of flame retardancy as well as thermal stability and some other special properties. Finally, we give a brief comment on the challenges and prospects of the future development of flame retardant bio-based benzoxazines.
\end{abstract}

\section{KEYWORDS}

Bio-based benzoxazine; curing mechanism; thermal stability; flame retardancy

\section{Introduction}

High-performance polymers are typical synthetic materials with excellent mechanical, electrical, and thermal properties, which can be continuously used under a high temperature. However, it is still a challenge to maintain the above outstanding properties while possessing good processability at the same time [1,2]. Polybenzoxazine is one of the few new polymers which have been commercialized successfully among many developed polymers over the past 40 years [3-5]. Polybenzoxazine is a relatively new class of polymeric phenolic resins with various excellent characteristics, including outstanding stiffness, low dielectric constant [6], high heat resistance, low flammability [7], and minimal moisture absorption when exposed to moisture, chemicals, and other corrosive liquid [8], therefore, they are ideal polymers to use in special and extreme cases. Moreover, benzoxazine monomers are safer and easier to operate and process because they can be stored at room temperature rather than harsh storage conditions, and do not release byproducts during the polymerization process with low volume shrinkage near zero [1], which ensures the dimensional stability and reduce the porosity of polymers. Thanks to these excellent properties, polybenzoxazine has been successfully applied in the fields of aerospace composite materials used in interior panels and bulkheads; insulating materials used in motors; electronic 
information industry such as printed circuit boards; mixing with epoxy resins to prepare copper-clad laminates and resin transfer molding technology [5,9].

Similar to other petroleum-based polymer materials, most of the widely used benzoxazine resins are prepared from fossil energy and facing environmental and ecological challenges. Fossil resources are heavily consumed with the rapid development of the world, but fossil energy as non-renewable resources have a very long regeneration cycle. Moreover, the mass production of fossil-based materials leads to many global problems, such as the increase of carbon dioxide concentration in the atmosphere, global warming, and other environmental issues [10,11]. Some materials used for benzoxazine resins are considered as potential harm to human health [12]. One of the most basic and widely used raw materials of benzoxazines is bisphenol A, which shows estrogen-mimicking and hormone-like influence with certain embryotoxicity and teratogenicity, limiting its use in food and beverage containers [13]. These problems bring about an increasing demand for the transition from fossil-based materials to sustainable and renewable resources in order to reduce dependence on fossil resources and make further contributions to solve environmental issues. The trend of using bio-based substances as raw materials to produce polymers is inevitable, which can minimize pollution and maximum use of resources [5]. Besides, some benzoxazine resins still have certain flammability, which potentially restricts their applications. Thus, it is necessary to develop green environmental protection and flame-retardant bio-based benzoxazine resins.

Bio-based materials use renewable natural resources like crops, plants, and their residues as raw materials to obtain polymer materials or monomers by chemical, biological and other methods, including bio-based platform compounds, bioplastics, and biofuels. Up to now, a great deal of bio-based benzoxazines has been already synthesized from many renewable phenolic sources such as cardanol [14], guaiacol [15], and urushiol [16]. Renewable amines are relatively few in comparison with phenolic sources, mainly furfurylamine. It is obvious that bio-based benzoxazines have attracted increasing attention over the past decades, which is proven by the number of publications. After searching in Web of Science using bio-based and benzoxazine as keywords, the number of open publications increased gradually over the past ten years (Fig. 1).

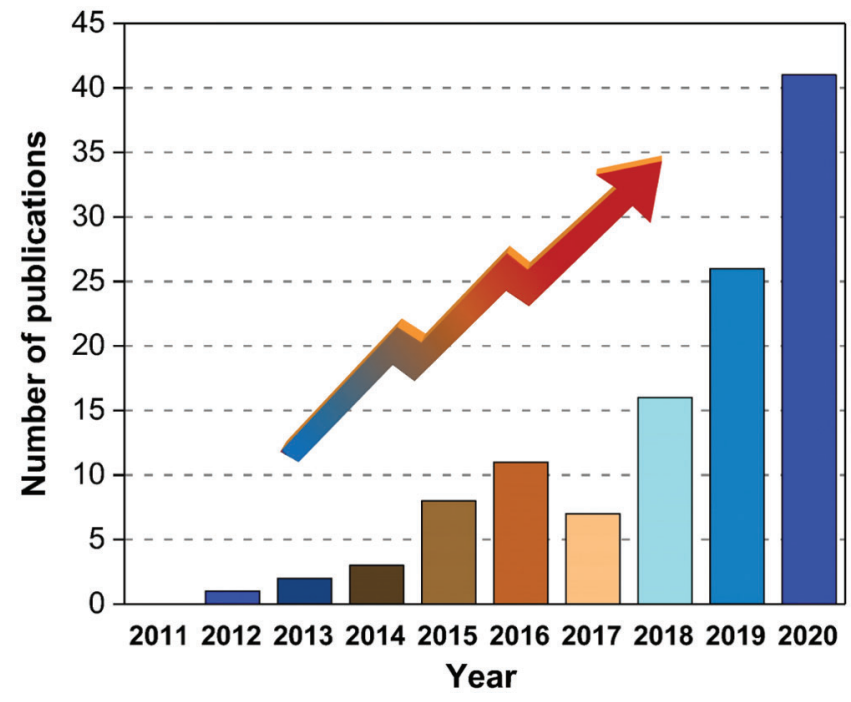

Figure 1: The annual number of publications using "bio-based and benzoxazine" as keywords in ISI-Web of Science 
In this review, the recent development of bio-based benzoxazines and their properties have been reviewed and summarized. The synthetic methods of benzoxazines are first introduced, including traditional solvent synthesis, solventless method, and microwave-assisted organic synthesis. The main emphasis is on the properties of bio-based benzoxazines such as mechanical property, thermal stability, flame retardancy, and so on. Furthermore, the curing behavior of benzoxazine is commented by the use of differential scanning calorimetry (DSC) and in-situ Fourier transform infrared spectroscopy (FTIR), curing kinetics and mechanism are also discussed and summarized. Finally, a brief summary of the opportunities and challenges for bio-based benzoxazines is given to expect better development of biobased benzoxazines in the future.

\section{Synthesis of Bio-Based Benzoxazine Monomers}

Benzoxazine monomers are obtained from the Mannich condensation reaction of phenol, amine, and formaldehyde or polyformaldehyde (Fig. 2) [4]. Thus, the selection of phenol and amine is wide, which offers high molecular design flexibility for the introduction of specific substituents to prepare benzoxazine monomers with excellent performance. The synthesis approaches of bio-based benzoxazine monomers remain similar to those observed in conventional benzoxazines, but extensive natural sources of phenols and amines make it possible to synthesize bio-based benzoxazines that are comparable to or superior to conventional petroleum materials. The synthesis methods of benzoxazine monomers mainly include traditional solvent synthesis, solventless method, and microwave-assisted organic synthesis.

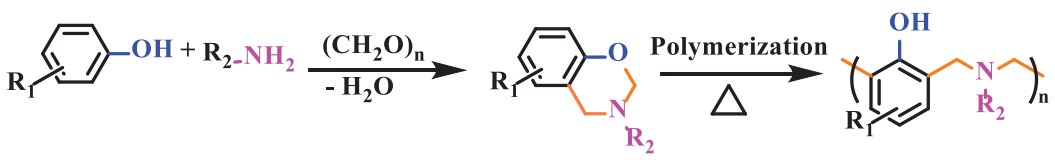

Figure 2: Synthesis and curing reaction of benzoxazine

The traditional solvent synthesis method is to dissolve phenol, amine, and formaldehyde or paraformaldehyde in a certain solvent, and then the homogeneous solution is heated for further reaction. Commonly used solvents include toluene, ethanol, N, N-dimethylformamide, 1, 4-dioxane, and so on. One-pot synthesis is the most common method and three reactants are mixed and dissolve in the solvent directly to heat to a high temperature so that a Mannich condensation reaction will occur. It is easy and convenient to control temperature, mix the reactants well with the low viscosity of the reaction system and obtain a high yield. This is where the superiority of this approach lies. However, it is difficult to select suitable solvents for reaction and it is necessary to consider whether solvents have negative or other effects on the reaction system. Moreover, this method will use many organic solvents which will pollute the environment and most organic solvents are harmful to human health.

No matter from the standpoint of economics or protecting the environment, solventless organic synthesis is an important synthesis method in green chemistry, which has attracted more and more attention and shows its unique charm. This method means that no solvents are used to dissolve the reactants. Three reactants are physically blended and then directly heated to a molten state, where a Mannich condensation reaction takes place to obtain benzoxazine monomers. The main advantage of this method is that there is no utilization of chemical solvents, which reduces the volatilization of solvent and the discharge of waste liquid. The operation is simple and the purity of the product is also very high. The main disadvantage of the solventless method is that not all reactions can be carried out without solvents and may need a higher temperature for reactions to occur. Although no solvent is used in the reaction process, a large amount of solvents is inevitably used in the subsequent separation process to obtain pure products. Various synthesis processes of bio-based benzoxazines are summarized in Table 1, including natural renewable phenol, amines, whether used or used what solvent in the reaction system, and subsequent purification process. 
Table 1: Reaction solvents, purification methods, phenols, and amines used in the synthesis of bio-based benzoxazines

\begin{tabular}{|c|c|c|c|c|c|}
\hline No. & Phenol & Amine & Reaction solvent & Purification method & Reference \\
\hline 1 & & & No solvent & Extracted with chloroform & {$[17]$} \\
\hline 2 & & & No solvent & $\begin{array}{l}\text { Filtered and extracted with } \\
\text { ethyl acetate }\end{array}$ & {$[18]$} \\
\hline 3 & & & DMSO & $\begin{array}{l}\text { Washed with } \mathrm{NaOH} \\
\text { solution and filtrate the } \\
\text { precipitate }\end{array}$ & [19] \\
\hline 4 & & & No solvent & Extracted from chloroform & {$[20]$} \\
\hline 5 & & & Dioxane & Recrystallized in ethanol & [21] \\
\hline 6 & & & Chloroform & $\begin{array}{l}\text { Washed with water and } \\
\mathrm{NaOH} \text { solution }\end{array}$ & {$[22]$} \\
\hline 7 & & & Toluene & $\begin{array}{l}\text { Extracted from petroleum } \\
\text { ether }\end{array}$ & {$[23]$} \\
\hline 8 & & & DMSO & $\begin{array}{l}\text { Washed with } \mathrm{NaOH} \\
\text { solution and collect the } \\
\text { precipitate }\end{array}$ & {$[24]$} \\
\hline 9 & & & No solvent & $\begin{array}{l}\text { Extracted with ethyl } \\
\text { acetate }\end{array}$ & {$[25]$} \\
\hline 10 & & & No solvent & $\begin{array}{l}\text { Dissolved in chloroform } \\
\text { and washed with water }\end{array}$ & {$[26]$} \\
\hline 11 & & $\mathrm{H}_{2} \mathrm{~N}$ & No solvent & Extracted with chloroform & {$[27]$} \\
\hline 12 & & & Toluene & $\begin{array}{l}\text { Recrystallized using } \\
\text { acetone/toluene in a } \\
1: 1 \text { ratio }\end{array}$ & {$[28]$} \\
\hline 13 & & & No solvent & No further purification & [29] \\
\hline
\end{tabular}




\begin{tabular}{lllll}
\hline Table 1 (continued). & & & \\
\hline No. Phenol & Rmine & Reaction solvent & Purification method & Reference \\
\hline 14 & $\begin{array}{l}\text { poly(ethylene } \\
\text { glycol) }\end{array}$ & $\begin{array}{l}\text { Recrystallized from } \\
\text { petroleum ether/ethyl } \\
\text { acetate }(10: 1)\end{array}$ \\
& No solvent & $\begin{array}{l}\text { No purification was carried [31] } \\
\text { out } \\
\text { Recrystallization from an } \\
\text { ethyl acetate/hexane } \\
\text { mixture (1:2) }\end{array}$ \\
\end{tabular}

In order to realize the principle of green chemistry, microwave-assisted organic synthesis has been widely used in the organic synthesis process to optimize the reaction conditions [14,32]. It can not only relatively shorten reaction time from hours to minutes, but also be considered as an energy-saving technology with high yield and high selective [30], which is more environmentally friendly compared with the other two methods. Jéssica and Lloyd used cardanol from cashew nutshell liquid and furfurylamine as renewable raw materials to synthesis bio-based benzoxazines in just 7 min with the help of microwave-irradiation as a heating source [14], while in traditional solvent methods, it needed more than $2 \mathrm{~h}$ [27]. The main disadvantage of microwave-assisted organic synthesis is that the reaction equipment is complex and expensive. Furthermore, the reaction is heated so fast that may lead to some danger and it is also difficult to maintain a certain temperature. Comparison between these three methods is presented in Fig. 3, indicating that microwave-assisted organic synthesis is the best method among the three methods, with the shortest reaction time, more environment-friendliness, and higher yield.
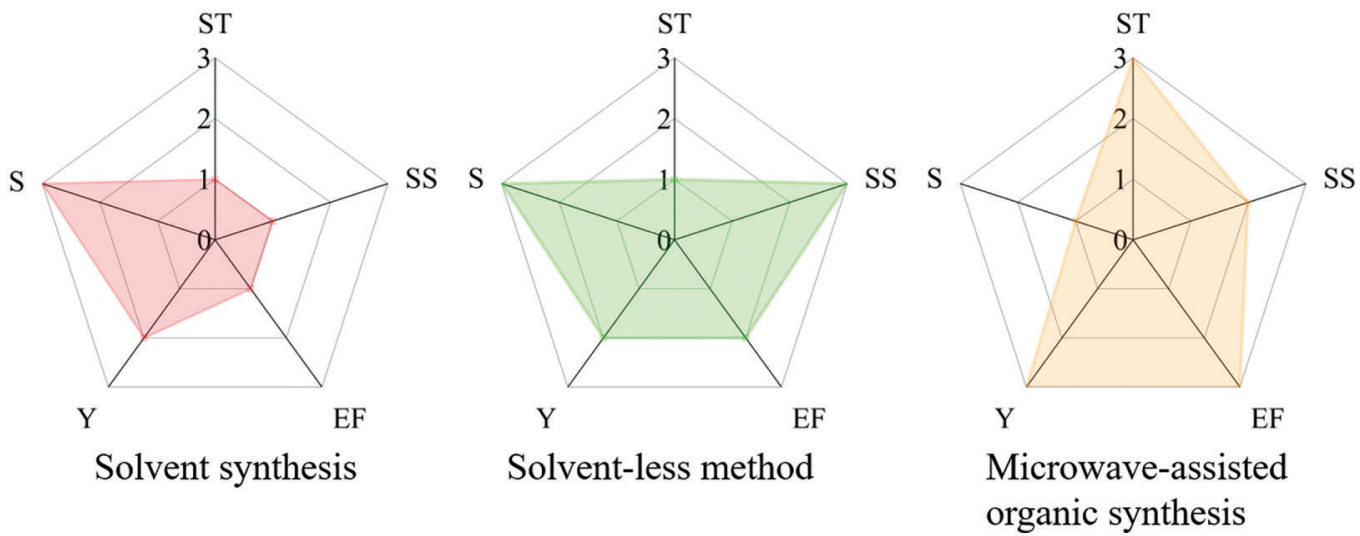

Figure 3: Schematic comparison of the most common benzoxazine production methods. Each method has been assessed in terms of saving reaction time (ST), Saving solvent (SS); Environment friendliness (EF); Yield (Y); Scalability (S). 1 = low, 2 = medium, 3 = high

\section{Curing Behavior of Benzoxazines}

\subsection{Polymerization Mechanism of Benzoxazine}

The polymerization process of benzoxazines mainly refers to the ring-opening polymerization of the oxazine ring, and the polymerization mechanism is complicated. The polymerization mechanism of 
benzoxazine can be simply divided into three steps: the ring-opening of the oxazine ring, followed by electrophilic attack and rearrangement process [33,34]. First, in the process of heating, the C-O bond on the oxazine ring is broken to form oxygen anion and carbocation. Then, the carbocation is attacked by the ortho-carbon connected to the oxygen atom of another oxazine ring, and the hydrogen atom in this position migrates to the oxygen anion to form a new phenolic hydroxyl group. Finally, the newly formed phenolic hydroxyl groups further catalyze the ring-opening of other oxazine rings to form a cross-linking network $[35,36]$. The proposed curing process of benzoxazines is shown in Fig. 4.

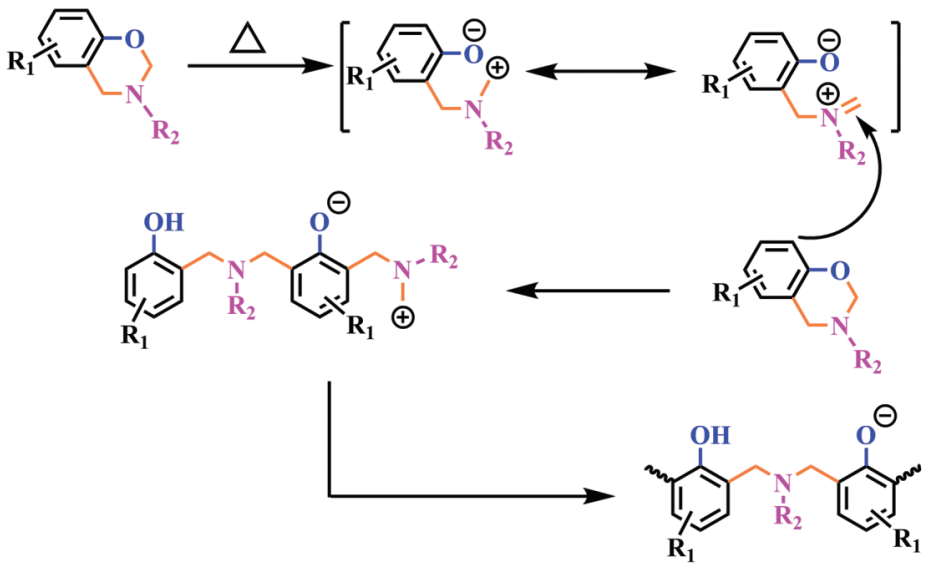

Figure 4: Process of ring-opening polymerization of benzoxazines

The ring-opening curing reaction of benzoxazine is carried out by the electrophilic substitution of carbocation [37]. Active intermediates may suffer an attack from all positions of the benzene ring of benzoxazine but most are ortho-position, including the aromatic amine ring of benzoxazine. Different degrees of reactivity will lead to a more complex polymerization mechanism. For instance, furfurylamine as a commonly used amine is widely used in the synthesis of bio-based benzoxazines. After the ringopening reaction, the formed carbocation will suffer an attack from the ortho-carbon of both oxazine ring and furan ring, resulting in a more complex cross-linking network [38]. Moreover, if the phenolic materials contain $\mathrm{C}=\mathrm{C}$ bonds in their chemical structure, $\mathrm{C}=\mathrm{C}$ bonds will also react during the hightemperature curing process to form complicated cross-linking networks. Teng et al. [30] proposed a more complex curing mechanism for the synthesized bio-based benzoxazines with $\mathrm{C}=\mathrm{C}$ bond and furfurylamine structure, as shown in Fig. 5.

Thermal polymerization is the most widely studied and most commonly used polymerization method [39], as well as acid-catalyzed polymerization and photo-initiated polymerization [40]. Monomer structures of benzoxazines will also affect the polymerization process. Some benzoxazine monomers contain phenolic hydroxyl and intramolecular hydrogen bonds in their chemical structures, which have the latent-catalyzed effect during the curing process $[3,41]$. 


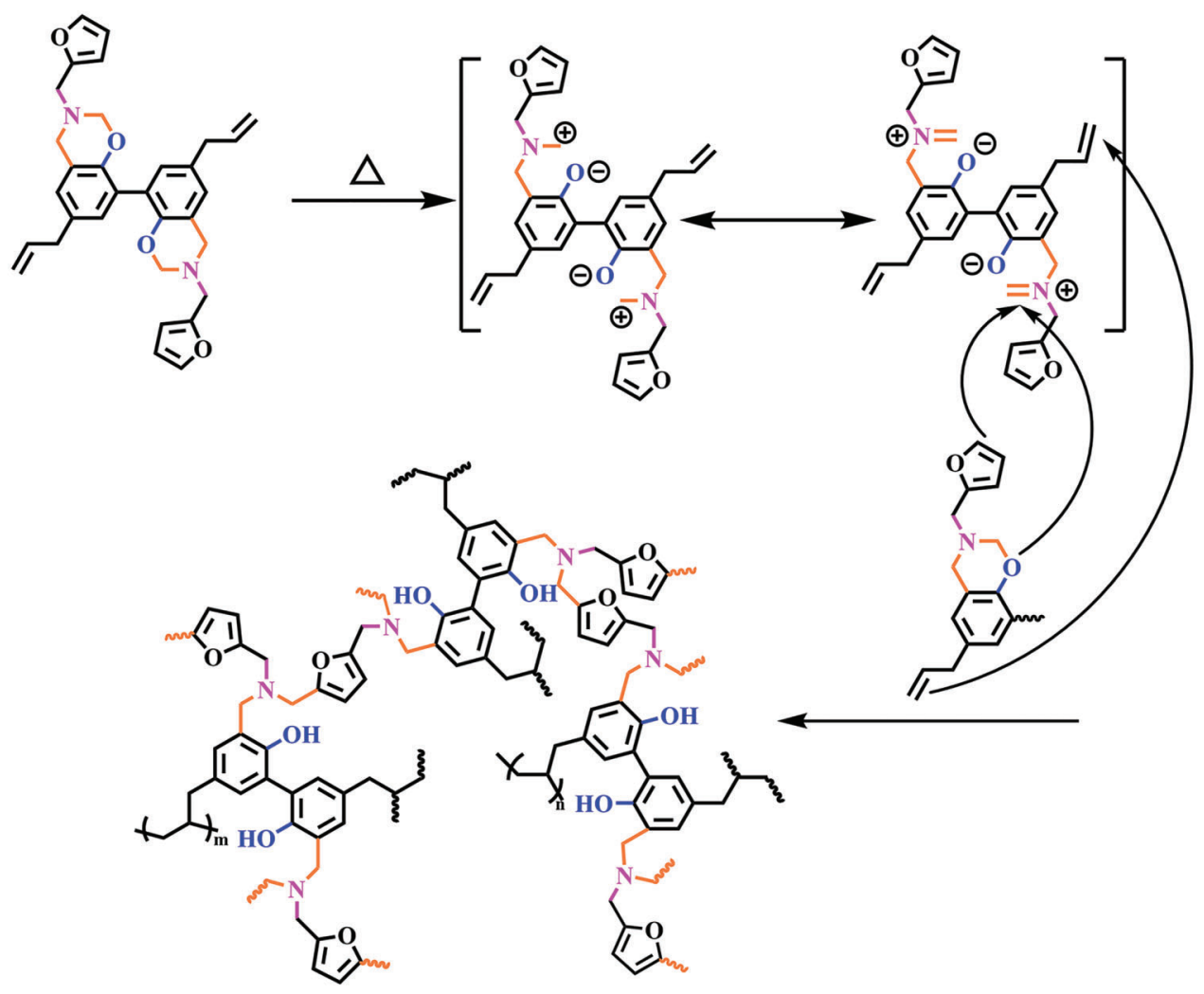

Figure 5: A more complex curing process of bio-based benzoxazines

\subsection{Characterization of Curing Mechanism}

The curing of benzoxazines is a complex physical and chemical reaction process. Curing reaction kinetics can not only describe the curing reaction process of the system but also study the effects of temperature, time, and composition on the curing system. It is significant to study the curing mechanism of benzoxazines and determine the curing conditions. DSC method is used to obtain curing characteristics from DSC curves, which is short, simple, and feasible so that it can be widely used in the study of curing kinetics. In-situ FTIR is used to monitor the structural changes of solid material at high temperatures. The weight of samples required for the test is relatively little and the operation is also simple and convenient in this test.

The DSC curve usually shows only two thermal events. The first one is an endothermic process, indicating the melting process of benzoxazine monomers. The second is a sharp exothermic peak, which represents the ring-opening polymerization of benzoxazine [17,42]. The onset temperature, exothermic peak temperature, and end temperature of polymerization can also be obtained from DSC curves [43,44]. There is only a single sharp exothermic peak in each curing system, which indicates that the benzoxazine monomers prepared are relatively pure [45]. Here is only a single exothermic peak, showing that there is no obvious side reaction occurring in the curing process.

In situ FTIR is utilized to further elaborate the curing process of benzoxazines. The change of the structure of benzoxazine during the heating process can be observed through FTIR curves at different temperatures [20]. The intensity of the characteristic peak of the oxazine ring obviously weakens or even disappears. 


\subsection{Effect of Side Groups on Curing Behaviors}

In his doctoral dissertation, Ohashi [46] studied the effect of substituents on the benzene ring of benzoxazine monomers in the curing process. The changing trend between the electronic effect of some electron-donating or withdrawing groups on the phenolic side and the polymerization temperature is observed. However, many substituents studied by Ohashi are not often seen in renewable raw materials, such as $-\mathrm{CN},-\mathrm{CF}_{3},-\mathrm{OCF}_{3}$, and so on. However, some acidic groups like phenolic hydroxyl group or carboxyl group, and long alkyl branched chains are more common in bio-based materials, which can relatively affect the curing behavior of the system.

\subsubsection{Effect of Acidic Functionality}

Phenolic hydroxyl. Phenolic hydroxyl is a kind of autocatalytic group, which can form an intermolecular hydrogen bond with the oxazine ring and induce the polymerization of benzoxazine at a lower temperature [47]. Once the intramolecular hydrogen bond sequence is destroyed during the heating process, the acidity of the phenol hydroxyl group is enhanced and free protons are released, which can catalyze the ring-opening polymerization of benzoxazines with a lower reaction temperature $[41,48]$.

There is a decrease in the melting point and polymerization temperature of bio-based benzoxazines containing hydroxyl groups. With the increase of phenolic hydroxyl content in the system, the exothermic peak on the DSC curve gradually shifts to lower temperature, which confirms that phenolic hydroxyl has a certain catalytic effect on the curing process and the curing temperature decreases [49]. Zhang et al. [41] used naringenin and furfurylamine as reactants to synthesize a fully bio-based benzoxazine and proposed a suitable mechanism of the inherent latent catalyst activity and ring-opening polymerization. Li et al. [50] investigated the effect of pyrogallol which served as a phenolic nucleophile on the curing process and kinetics of bio-based benzoxazines with phenol as a contrast. The curing kinetic parameters of E-s and E-s/py were calculated by the Kissinger equation and the Ozawa equation, which showed that the addition of phenolic hydroxyl decreased the apparent activation energy of the curing system. Apparent activation energy is calculated according to these two equations, as shown below [50]:

Kissinger equation $\ln \frac{\beta}{T_{p}^{2}}=\ln \frac{A R}{E_{a}}-\frac{E_{a}}{R T_{p}}$

Ozawa equation $\ln \beta=-1.052 \frac{E_{a}}{R T_{p}}+\mathrm{C}$

Therefore, it is of great significance to synthesize a series of bio-based benzoxazine with latent catalytic activity based on the phenolic hydroxyl group as a part of its monomer structure.

Carboxyl group. Various acids can be used as additives to catalyze the ring-opening and polymerization process of benzoxazine. It is obvious that benzoxazine monomers containing the carboxyl group exhibit lower polymerization temperature by comparing the curing parameters [51]. Not only the exothermic peak corresponding to polymerization temperature but also the endothermic peak relating to the melting point are lower than those of classical benzoxazine monomers due to the carbonyl group and the differences in the reactivity.

Andreu et al. [52] discussed the effect of acidic groups on the polymerization process of benzoxazine monomers and considered that the polymerization temperature was not related to the electronic effect of side groups, but related to the acidity of substituents, which catalyzed the ring-opening reaction by increasing the concentration of oxonium species. Zhan et al. [53] proposed that both $\mathrm{O}$ atoms with strong electronegativity in hydroxyl, carboxyl and furan rings and $\mathrm{N}$ atoms in amino groups can act as sites for hydrogen bonds in polymer chains. The existence of hydrogen bonds could promote the ring-opening of 
the oxazine ring too. The acidic functional group preferentially interacts with the oxygen atoms in the monomer, promoting the ring-opening reaction as well.

\subsubsection{Effect of Long-Branched Chains}

Long alkyl chains. Compared with other bio-based materials, the most prominent feature of cardanol is that it has a long alkyl chain containing $\mathrm{C}=\mathrm{C}$ bonds. The complex structure of cardanol results in a more complex curing process and mechanism of benzoxazines. Compared with other bio-based benzoxazines, cardanol-based benzoxazines show a lower melting point and a $\mathrm{T}_{\mathrm{g}}$. It melts at a lower temperature because of the low chain stacking efficiency in the presence of aliphatic side chains. Ganfoud et al. [54] investigated the role of the alkyl side chain of cardanol on benzoxazine polymerization and polymer properties. They designed the experiment through bridging ethylene diamine with two phenols, one phenol, and one cardanol, or two cardanol to synthesize three functional benzoxazine monomers (Fig. 6a) and evaluated the effect of side chains on the kinetics of polymerization.

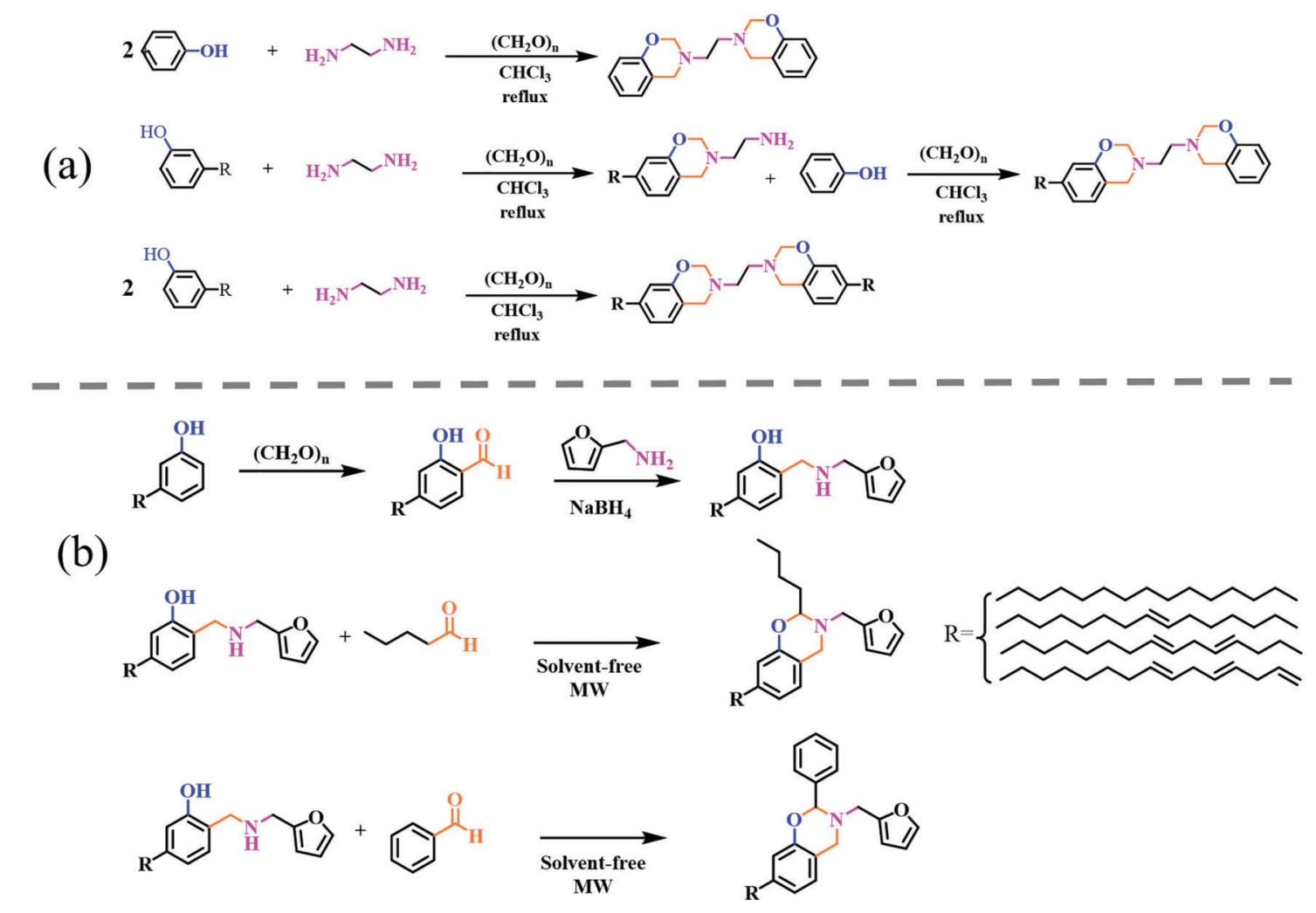

Figure 6: (a) Synthesis of three benzoxazines in Ganfoud's experiment; (b) Design of two benzoxazines with branched chain on the oxazine ring. Group $\mathrm{R}$ in (a) and (b) is the same

The introduction of a branched chain to the oxazine ring will also affect the curing behavior of benzoxazines. Compared with unsubstituted benzoxazines, substituted benzoxazines have lower activation energy values and polymerization temperatures. It could be explained by the electronic and inductive effects of the novel groups substituted in the oxazine ring. The $\mathrm{C}-\mathrm{O}$ bond on the oxazine ring is broken to form oxygen anion and carbocation during the heating process and the alkyl and aromatic substituents on the oxazine ring can stabilize the formed intermediates by inductive and hyper conjugative effect, which can be further verified by the enthalpy values of the polymerization [55]. Pereira et al. synthesized 
two bio-based benzoxazines (Fig. 6b) and assessed the influence of the substituents on the oxazine ring during the polymerization process.

Aliphatic amine with long chains. Not only furfurylamine but also many other amines like stearylamine, aniline, and 1, 4-phenylenediamine can be used as reactants when synthesizing benzoxazines. But stearylamine, aniline, and 1, 4-phenylenediamine can only react with bio-based phenols to obtain partly bio-based benzoxazines rather than fully bio-based benzoxazines. Different from aromatic amines, there is a long alkyl group in the chemical structure of stearylamine. Different amines also affect the curing behaviors of benzoxazines. When using the same phenol, the curing temperature of stearylamine-based benzoxazines is higher than that of furfurylamine-based benzoxazines due to the electrophilic substitution reaction of the furan ring [56]. Besides, the furan ring can provide additional cross-linking sites to participate in the curing reaction. The melting point of benzoxazines synthesized by stearylamine is also lower due to the presence of the long aliphatic chain. Moreover, the molecular chain of stearylamine is more flexible compared with aromatic amines, which leads to a lower glass transition temperature.

\section{Properties of Bio-Based Benzoxazines}

\subsection{Benzoxazine Thermosets Derived from Bio-Based Phenols and Bio-Based Amines}

Thermal stability. Thermogravimetric analysis (TGA) is used to quantitatively evaluate the thermal stability thermal-oxidative decompositions of the synthesized bio-based benzoxazine under nitrogen and air atmosphere. The thermomechanical properties of bio-based benzoxazine are studied by dynamic mechanical analysis (DMA) and thermomechanical analysis (TMA) [20]. It has been demonstrated that furan groups participate in the ring-opening reaction and increase the crosslinking density of benzoxazine polybenzoxazine systems [28]. Thus, the existence of the furan ring structure improves the thermal stability of the system and promoting carbon formation of the system [57,58]. Furthermore, the $\mathrm{Tg}$ value of furfurylamine-based benzoxazines is also higher than that of the commercial benzoxazines.

Zhan et al. [53] synthesized diphenolic acid-based benzoxazines with furfurylamine (DPA-F) or aniline (DPA-A) (Fig. 7) and compared with traditional fossil-based benzoxazine using bisphenol A and aniline (BPA-A). Under nitrogen conditions, the $\mathrm{T}_{5 \%}$ and char residual of DPA-F were $340^{\circ} \mathrm{C}$ and $50.2 \%$ respectively, which were much higher than those of DPA-A $\left(330^{\circ} \mathrm{C}\right.$ and $\left.37.4 \%\right)$ and BPA-A $\left(331^{\circ} \mathrm{C}\right.$ and $30.6 \%)$. DPA-F had the highest $\mathrm{T}_{\max }\left(449^{\circ} \mathrm{C}\right)$ and the lowest decomposition rate compared with the other two benzoxazines in the nitrogen atmosphere, while TGA and DTG of these three benzoxazines exhibited no obvious difference in air atmosphere. Therefore, DPA-F under air atmosphere did not present outstanding thermal properties, which limited the further application of the material under high temperatures.

Flame retardancy. The correlation between crosslinking structure and flammability of cured benzoxazine resin is further analyzed by microscale combustibility (MCC). The introduction of the furan ring can further improve the crosslinking density of the system and give the synthesized bio-based benzoxazine higher thermal stability, charring ability, and fire resistance, which can reduce the total heat release (THR) and heat release capability (HRC) of fully bio-based benzoxazine. Thanks to the higher char yield, bio-based benzoxazines containing furfurylamine exhibit perfect flame retardancy in limit oxygen index (LOI) and vertical combustion (UL-94) test. When synthesizing benzoxazine monomers, phosphorus-containing groups like DOPO can also be introduced to further enhance the flame retardancy of the monomers [59]. Furthermore, some silicon-containing monomers can also be introduced into benzoxazine monomers to prepare some composite material with better properties such as low water absorption, excellent mechanical property, flame retardancy, and so on $[18,60,61]$.

Lin et al. [38] achieved high-performance bio-based benzoxazines from renewable materials like furfurylamine and vanillin-derived biphenol (Fig. 8), which showed perfect flame retardancy with a high 
LOI value of more than $60 \%$ and V-0 level in the UL-94 test. However, they did not further study the flammability of the polybenzoxazine and do MCC tests to evaluate the effect of the introduction of the DOPO group on the heat release of the system.
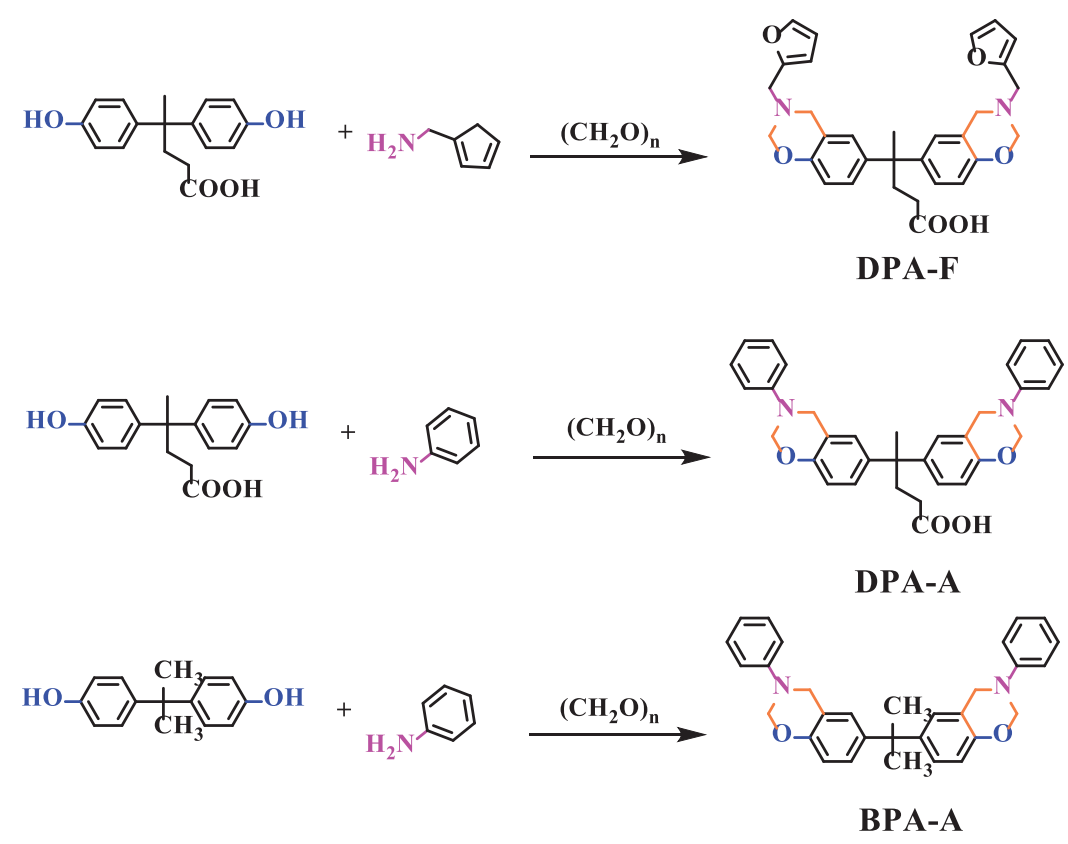

Figure 7: Synthesis of DPA-F, DPA-A, and BPA-A
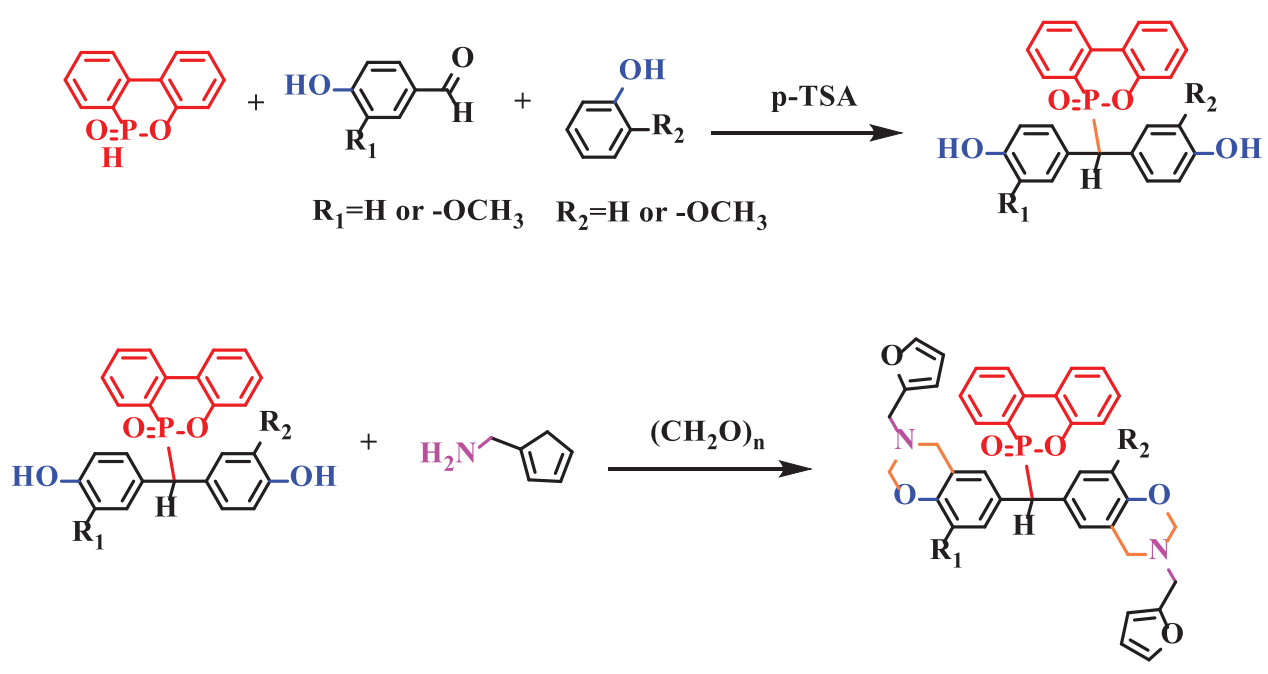

Figure 8: Synthesis of benzoxazines containing DOPO group

Storage modulus. The furan ring structure provides additional cross-linking points in the process of ring-opening polymerization, which increases the cross-linking density of the polymer $[45,57]$. The storage modulus and glass transition temperature of the system are also significantly increased [3].

Antibacterial and algaecidal properties. $\mathrm{Lu}$ et al. [62] reported a variety of main-chain-type benzoxazine polymers (MCBPs) which were synthesized from renewable raw material daidzein, 
furfurylamine, polyetheramine, and paraformaldehyde. Interestingly, due to the existence of daidzein and furan units, these cured MCBP films showed excellent antibacterial and algaecidal properties while maintaining good thermal stability at the same time. Algae cells on the surface of MCBPs showed a state of accumulation with a large amount of flocculent cell debris around it, indicating that the polybenzoxazine film had toxic effects on both kinds of algae and had good algae resistance activity. Benzoxazine can have a broader application prospect in some special environments like in marine antifouling coating because of this biotoxicity.

Anticorrosion property. Zhang et al. [56] synthesized a novel bio-based benzoxazine (D-Bz) and prepared a series of copolymers by using D-Bz and other two benzoxazines (S-Bz and F-Bz) (Fig. 9). Results showed that when the ratio of S-Bz: D-Bz: F-Bz was 1:6:3, the copolymer had good synergistic effects with a lower dielectric constant, higher crosslink density, lower corrosion current and anticorrosion properties. It is proved that benzoxazine has a broad application prospect in reducing electrochemical corrosion and prolonging the service life of steel. However, they did not explore whether the immersion and degradation of benzoxazine monomers in water for a long time is harmful to aquatic animals and plants.

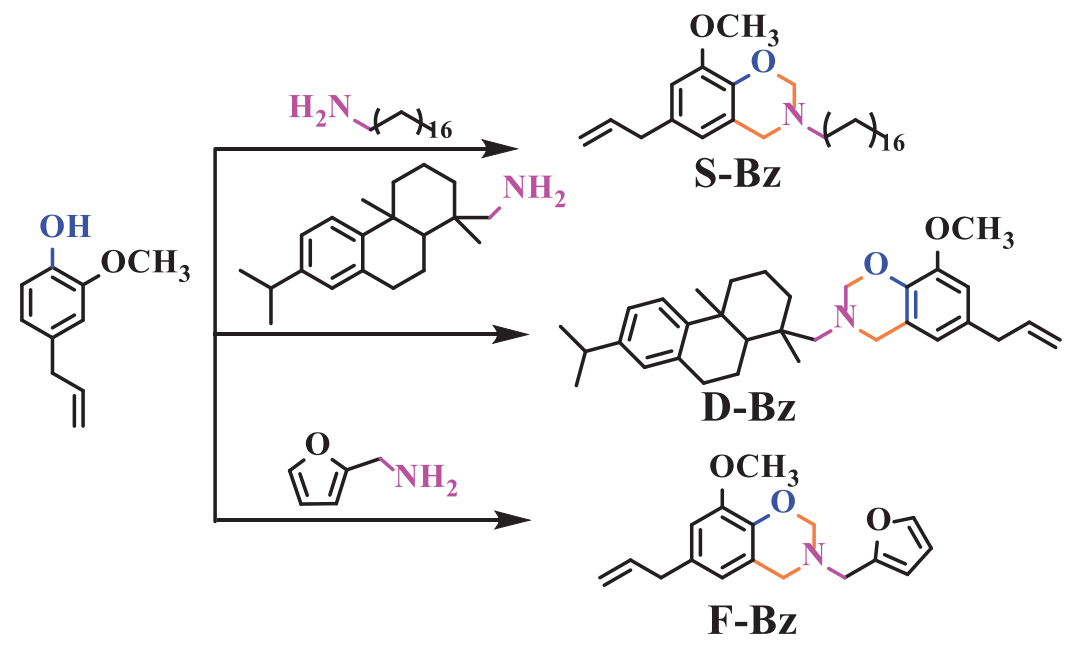

Figure 9: Synthesis of S-Bz, D-Bz, and F-Bz

Some thermal parameters and properties of fully bio-based benzoxazines are summarized in Table 2, including $\mathrm{T}_{\mathrm{g}}, \mathrm{T}_{\text {polymerization }}, \mathrm{T}_{\text {decomposition, }}$, char yield, and flame retardancy. It can be seen that fully biobased benzoxazines possess outstanding thermal stability with high decomposition temperature and char yield. The increase of the furan ring structure of the system means that there are more cross-linking sites in the curing process, resulting in higher cross-linking density. Higher $\mathrm{T}_{\mathrm{g}}$ may mean higher curing temperature and more difficulty for processing. Flame retardancy is mainly manifested in higher LOI value or V-0 rating in the UL-94 tests and lower heat release in the MCC test. Some special properties of fully bio-based benzoxazines are also mentioned in Table 2 .

\subsection{Benzoxazine Thermosets Derived from Bio-Based Phenols}

Different from furfurylamine, which is mainly used as amine sources now, some aromatic amines or aliphatic amines can also be used to synthesize benzoxazine monomers. The difference of amines will also have effects on the properties of polybenzoxazine. 
JRM, 2022, vol.10, no.4

Table 2: Thermal characterization of fully bio-based benzoxazine and some other properties

\begin{tabular}{|c|c|c|c|c|c|c|c|c|c|c|c|}
\hline \multirow[t]{2}{*}{ Structure } & \multirow[t]{2}{*}{$\begin{array}{l}\mathrm{T}_{\mathrm{g}} \\
\left({ }^{\circ} \mathrm{C}\right)\end{array}$} & \multicolumn{2}{|c|}{$\begin{array}{c}\mathrm{T}_{\text {polymerization }} \\
\left({ }^{\circ} \mathrm{C}\right)\end{array}$} & \multicolumn{2}{|c|}{$\begin{array}{c}\mathrm{T}_{\text {decomposition }} \\
\left({ }^{\circ} \mathrm{C}\right)\end{array}$} & \multirow[t]{2}{*}{$\begin{array}{l}\text { Char yield } \\
(\%)\end{array}$} & \multicolumn{3}{|c|}{ Flame retardancy } & \multirow[t]{2}{*}{$\begin{array}{l}\text { Other } \\
\text { property }\end{array}$} & \multirow[t]{2}{*}{ Reference } \\
\hline & & $\mathrm{T}_{\mathrm{o}}$ & $\mathrm{T}_{\mathrm{p}}$ & $\mathrm{T}_{5 \%}$ & $\mathrm{~T}_{10 \%}$ & & $\begin{array}{l}\text { LOI } \\
(\%)\end{array}$ & $\begin{array}{l}\mathrm{HRC} \\
\left(\mathrm{J} \cdot \mathrm{g}^{-1} \cdot \mathrm{K}^{-1}\right)\end{array}$ & $\begin{array}{l}\text { THR } \\
\left(\mathrm{kJ} \cdot \mathrm{g}^{-1}\right)\end{array}$ & & \\
\hline & $312^{*}$ & 193 & 229 & 346 & 403 & 64 & - & 54 & 9.3 & - & {$[28]$} \\
\hline & - & 187 & 203 & 304 & 370 & 53 & - & 37 & 8.3 & - & {$[58]$} \\
\hline & $148 * *$ & 198 & 222 & 361 & 394 & 53.8 & $39 * * *$ & - & - & - & {$[57]$} \\
\hline & - & 150 & 185.3 & 340 & 449 & 50.2 & - & 88 & 14.1 & & {$[53]$} \\
\hline & $286^{* *}$ & 189 & 252 & 301 & 404 & 64 & - & 31.9 & 6.6 & - & [41] \\
\hline & - & 179 & 205 & 351 & 395 & 65 & - & - & - & - & {$[63]$} \\
\hline & - & 215 & 251 & 320 & 348 & 56 & - & 70.6 & 6.5 & - & {$[20]$} \\
\hline & - & 190 & 198 & 363 & 427 & 55 & - & - & - & - & {$[64]$} \\
\hline & $148^{* *}$ & 169 & 210 & 375 & 405 & 54 & $39.1 * * *$ & - & - & Anticorrosion & {$[56]$} \\
\hline & $303 * *$ & - & 229 & 440 & 463 & 61 & - & - & - & $\begin{array}{l}\text { Good } \\
\text { processability }\end{array}$ & {$[30]$} \\
\hline
\end{tabular}

Note: $\mathrm{T}_{\mathrm{g}}$ value was reported from TMA* and DMA**.

$\mathrm{T}_{5 \%}, \mathrm{~T}_{10 \%}$, and char yield was obtained from TGA in nitrogen.

$* * * \mathrm{LOI}=17.5+0.4 \times($ char yield, $\%)$. 
Thermal stability. Compared with that of fully bio-based benzoxazines, the thermal stability of biobased benzoxazines synthesized from arylamine or aliphatic amine is poor, reflecting from the lower $\mathrm{T}_{5 \%}$, $\mathrm{T}_{10 \%}$, and char yield $[55,65]$. This is mainly because the furan ring can provide additional cross-linking sites for ring-opening polymerization reaction compared with the aromatic ring, which can promote higher cross-linking density of the system and improve the thermal stability of polybenzoxazine with high decomposition temperature and char yield. Oliveira et al. [32] reported six kinds of benzoxazine monomers prepared from guaiacol (Fig. 10) and compared their curing behavior and thermal stability. There was no doubt that benzoxazine monomers containing furan rings had the lowest polymerization temperature and the highest degradation temperature, indicating that the monomer had outstanding processability and thermal stability. However, they did not give a good explanation for the effect of aromatic amines which was substituted at different position of the aromatic ring, on the curing behavior and thermal stability, for example, the difference between $p$-toluidine and $o$-toluidine.

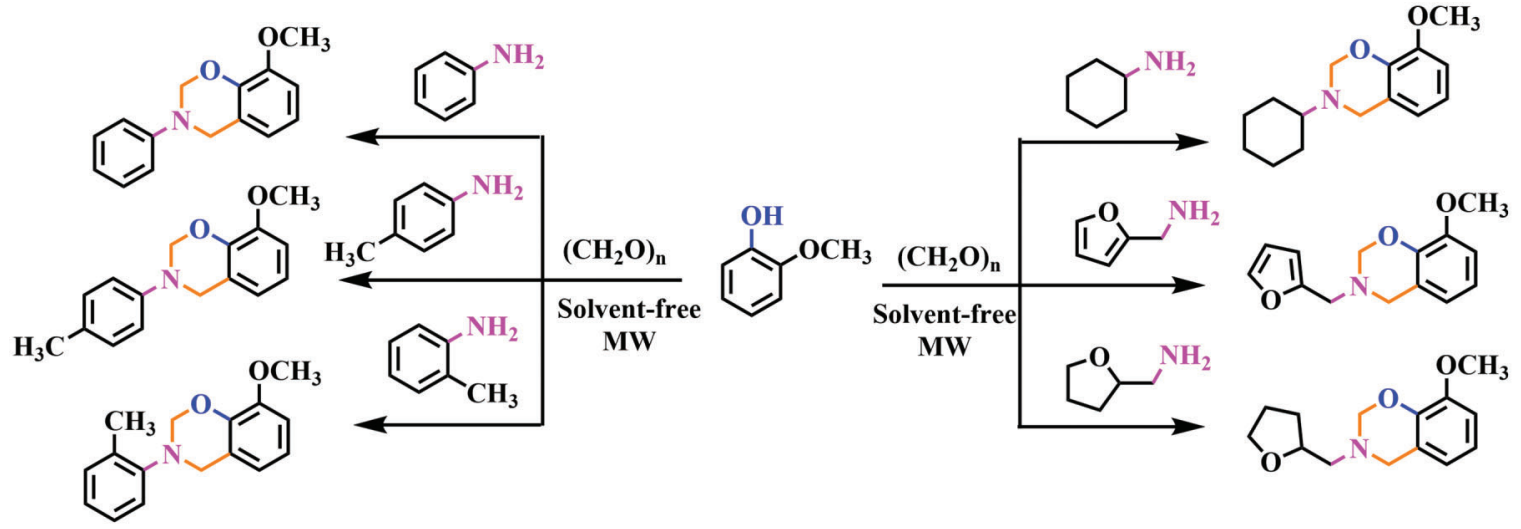

Figure 10: Synthesis of six kinds of benzoxazines with different amines

Flame retardancy. In general, compared with aliphatic polymers, aromatic polymers possess higher thermal stability because aromatic structures are easy to carbonize rather than simply decomposed under high temperatures. Thus the flame retardancy of benzoxazine synthesized from aliphatic amine is worse than that of aromatic amine and furfurylamine-based benzoxazine with much higher HRC and THR values in the MCC test.

Two kinds of daidezein-based benzoxazine resins (Dd-ddm and Dd-hda) were synthesized and compared the thermal stability and flame retardancy between them [66]. Poly(Dd-ddm) ${ }_{\text {main }}$ exhibited good thermal stability with a higher $\mathrm{T}_{5 \%}$ value $383^{\circ} \mathrm{C}$ than that of poly(Dd-hda) ${ }^{\mathrm{X}}$ main $346^{\circ} \mathrm{C}$ and $\mathrm{T}_{10 \%}$ $\left(426^{\circ} \mathrm{C}\right)$ while the value of poly $(\mathrm{Dd}-\mathrm{hda})^{\mathrm{X}}{ }_{\text {main }}$ was $383^{\circ} \mathrm{C}$ in nitrogen. Similarly, poly $(\mathrm{Dd}-\mathrm{ddm})^{\mathrm{X}}$ main possessed lower HRC $\left(27.1 \mathrm{~J} \cdot \mathrm{g}^{-1} \cdot \mathrm{K}^{-1}\right)$ and THR $\left(8.4 \mathrm{~kJ} \cdot \mathrm{g}^{-1}\right)$ in the MCC test, indicating good flame retardancy. But at the same time, the high glass transition temperature of this system may cause some difficulties for processing.

Wang et al. [67] reported a bio-derived benzoxazine monomer (BHDB-Bz) using desoxyanisoin and furfurylamine and compared it with benzoxazines (BPA-Bz) synthesized from bisphenol A and furfurylamine. Benefitting from the superior char formation ability, BHDB-Bz presented remarkable antiflammability and reached V-0 level in the UL-94 test. Photographs in the UL-94 vertical burning tests are shown in Fig. 11. Moreover, it had a higher LOI value of $40 \%$ and lower HRR $\left(35.5 \mathrm{~J} \cdot \mathrm{g}^{-1} \cdot \mathrm{K}^{-1}\right)$ and THR $\left(3.4 \mathrm{~kJ} \cdot \mathrm{g}^{-1}\right)$ test due to its high crosslinking density and outstanding charring ability. 


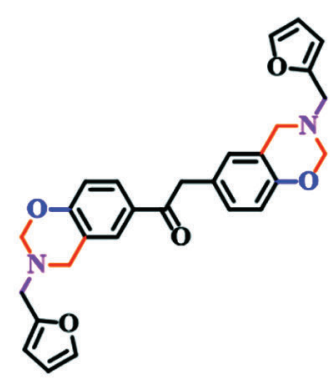

BHDB-Bz

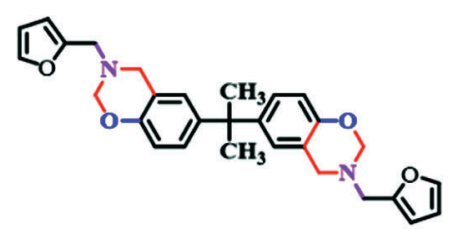

BPA-Bz
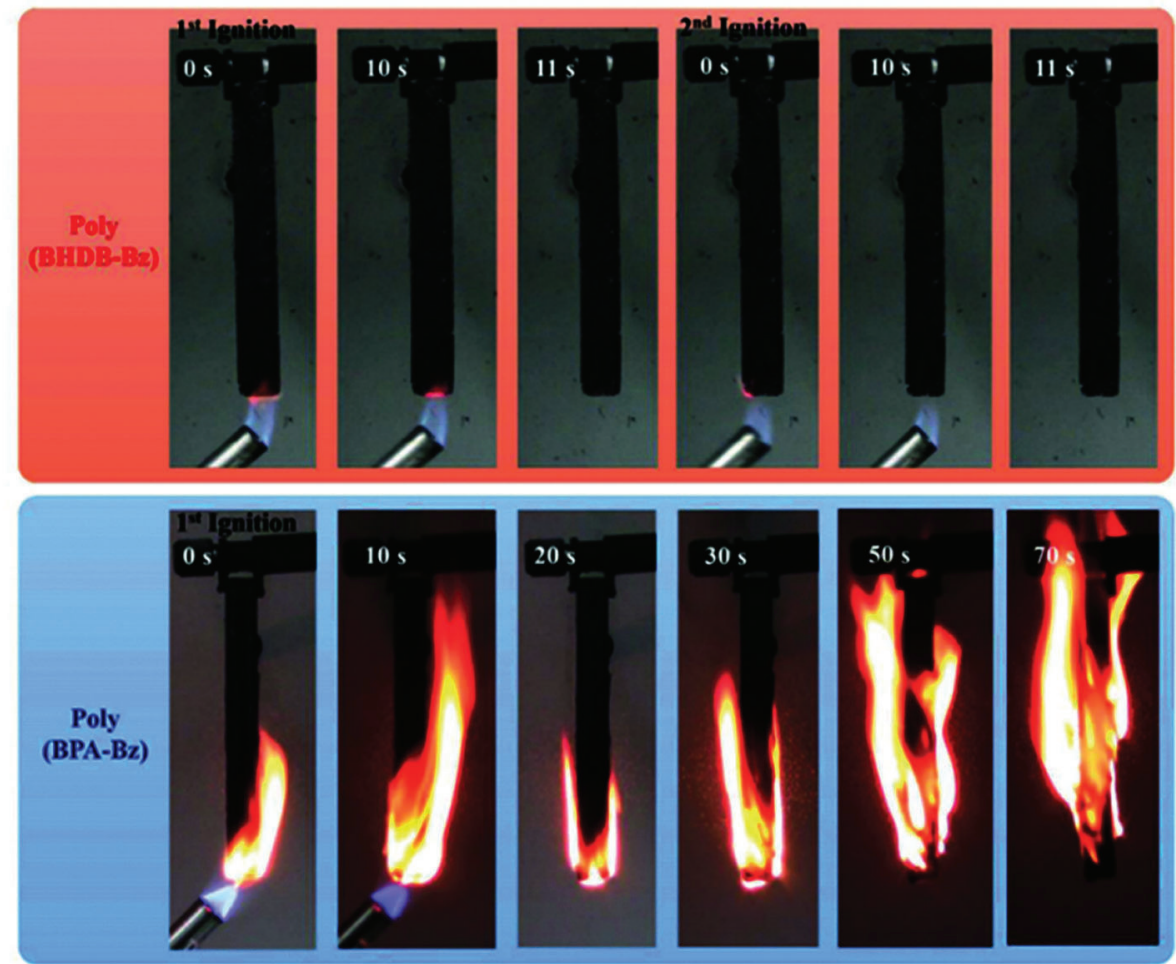

Figure 11: Photographs in the UL-94 vertical burning test of poly(BHDB-Bz) and poly(BPA-Bz) and the structure of BHDB and BPA. Reproduced with permission from reference [67]. Copyright 2021 Elsevier

Moreover, other elements, such as phosphorus and silicon, can also be introduced into benzoxazine monomers to improve flame retardancy and smoke suppression. Amarnath et al. [68] reported environmentally friendly cardanol-based polyphosphazene polybenzoxazine networks (Fig. 12) with excellent mechanical properties, high LOI value (33\%), UL-94 V-0 rating, and lower smoke density. But the synthesis process was so complex that it was almost impossible for large-scale production. Fig. 13 exhibits the SEM images of the residual chars. It is found that the residual chars became more intact and intumescent with increasing the cardanol-based polyphosphazene polybenzoxazine content.

Hydrophobicity. The introduction of silicon-containing groups or silica particles doped in the curing process of benzoxazine monomers can improve the thermal stability and char yield of benzoxazines Moreover, benzoxazine films obtain some special properties such as outstanding hydrophobicity, corrosion resistance, anti-ultraviolet property, and oil/water separation, indicating that the application of benzoxazine has a promising future [69].

Some thermal parameters and properties of benzoxazines derived from bio-based phenols are summarized in Table 3, including $T_{\mathrm{g}}, \mathrm{T}_{\text {polymerization, }} \mathrm{T}_{\text {decomposition, }}$, char yield, flame retardancy, and some other properties. Compared with fully bio-based benzoxazines, the decomposition temperature of benzoxazines listed in Table 3 is relatively low. The increase of the aromatic ring structure of the system will also increase the char yield. The flame retardancy of these benzoxazines is not very good without the cooperation of other elements like phosphorus.

\subsection{Benzoxazine Thermosets Derived from Bio-Based Amines}

The most commonly used bio-based amines are furfurylamines while various phenols can be chosen for the synthesis of benzoxazine monomers, both including bio-based phenols and petroleum-based phenols. 
Different phenols also have some effects on the properties of benzoxazine monomers. Usually, petroleumbased benzoxazines, like benzoxazines synthesized from bisphenol A, are used as contrast samples in experiments, so their properties are often worse than those of full-biological benzoxazines, such as mechanical properties thermal stability, flame retardancy, and so on.

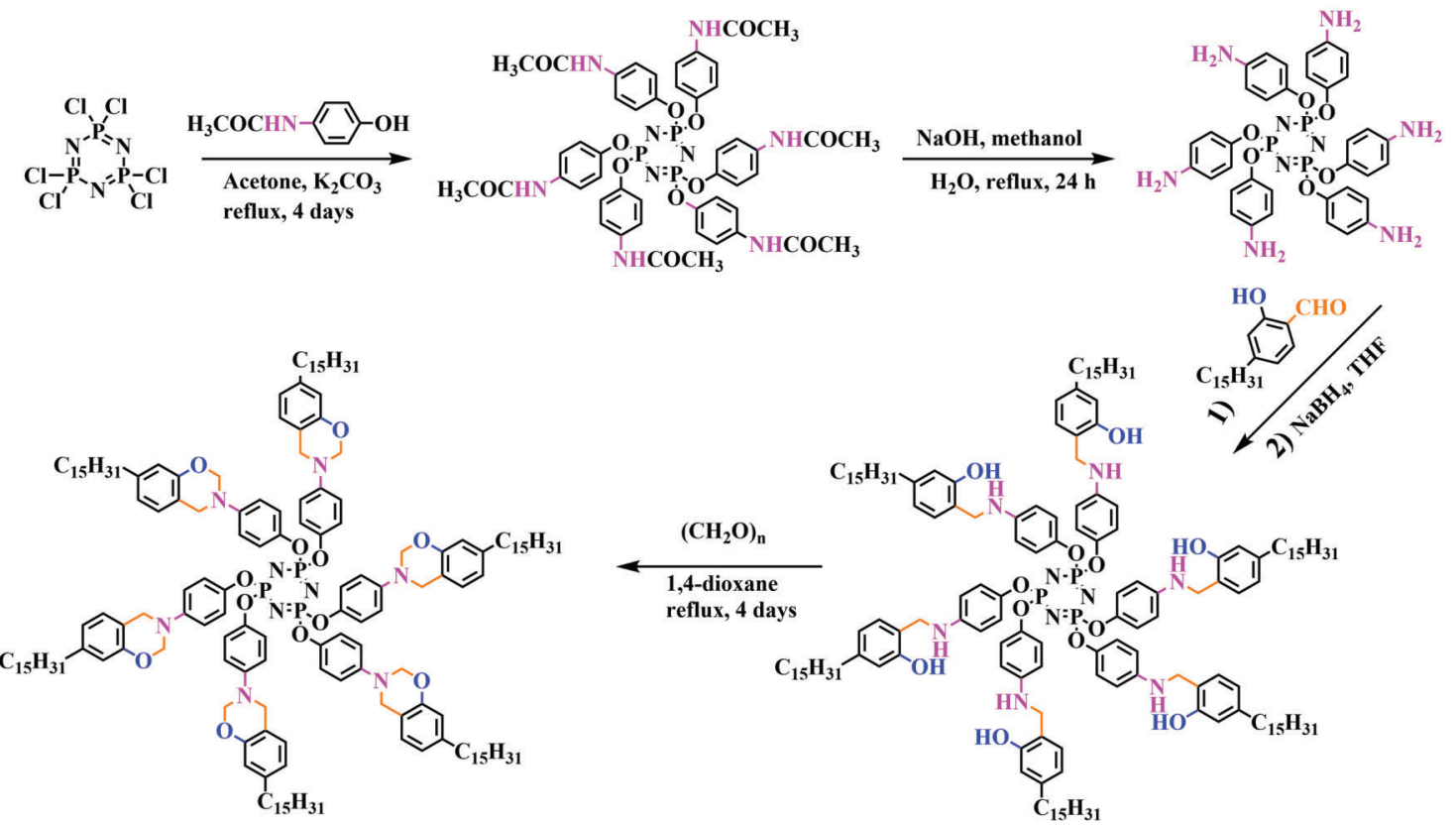

Figure 12: Synthesis of cardanol-based phosphazene benzoxazine monomer
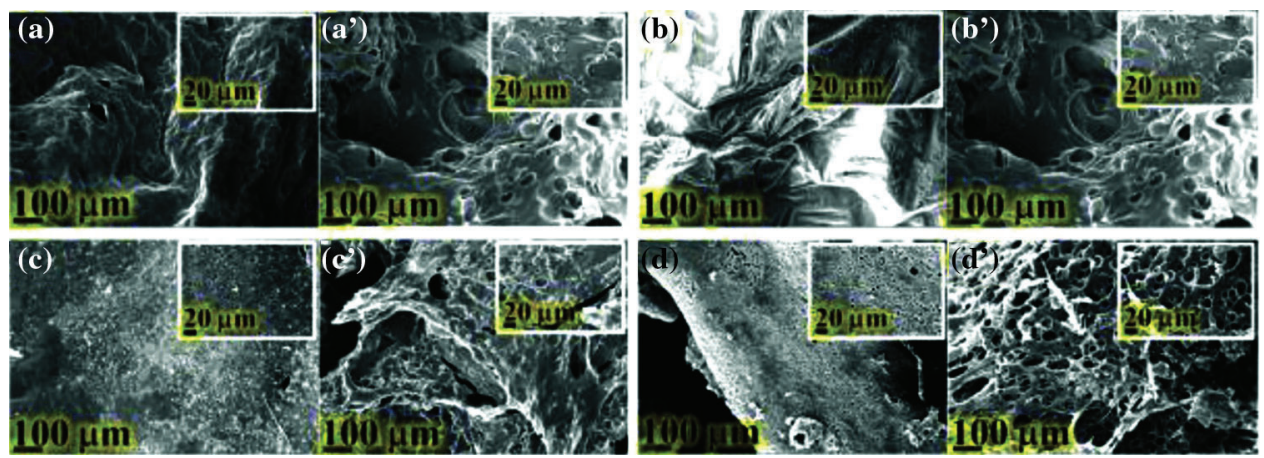

Figure 13: SEM images of (a, b, c, d) exterior and (a', b', c', d') interior surfaces of residual char: (a, a') poly $\left(\mathrm{C}_{\mathrm{PN}} 0\right),\left(\mathrm{b}, \mathrm{b}^{\prime}\right) \operatorname{poly}\left(\mathrm{C}_{\mathrm{PN}} 10\right),\left(\mathrm{c}, \mathrm{c}^{\prime}\right)$ poly $\left(\mathrm{C}_{\mathrm{PN}} 80\right)$ and $\left(\mathrm{d}, \mathrm{d}^{\prime}\right)$ poly $\left(\mathrm{C}_{\mathrm{PN}}\right)$. Reproduced with permission from reference [68]. Copyright 2018 American Chemical Society

Thermal stability. Generally, if the thermal stability of the used phenols is better than that of bisphenol A [72], or if the structure can provide additional cross-linking sites during the curing process and increase the cross-linking density of the system [73], the thermal stability of the whole system can be improved accordingly. Lyu used 4, 4'-thiobisphenol as a phenol resource to synthesize three benzoxazine monomers (Fig. 14) [72]. The significant improvement for the thermal stability of poly(TBP-a) and poly(TBP-fa) 
was attributed to that sulfur atom replaced the isopropylidene moiety in bisphenol A structure, which was easy to cleave to release methyl groups during the combustion process. But they did not analyze the composition of gases produced during combustion, whether it released more toxic gases in the combustion process due to the introduction of sulfur atoms.

Table 3: Thermal characterization of benzoxazines derived from bio-based phenols and some other properties

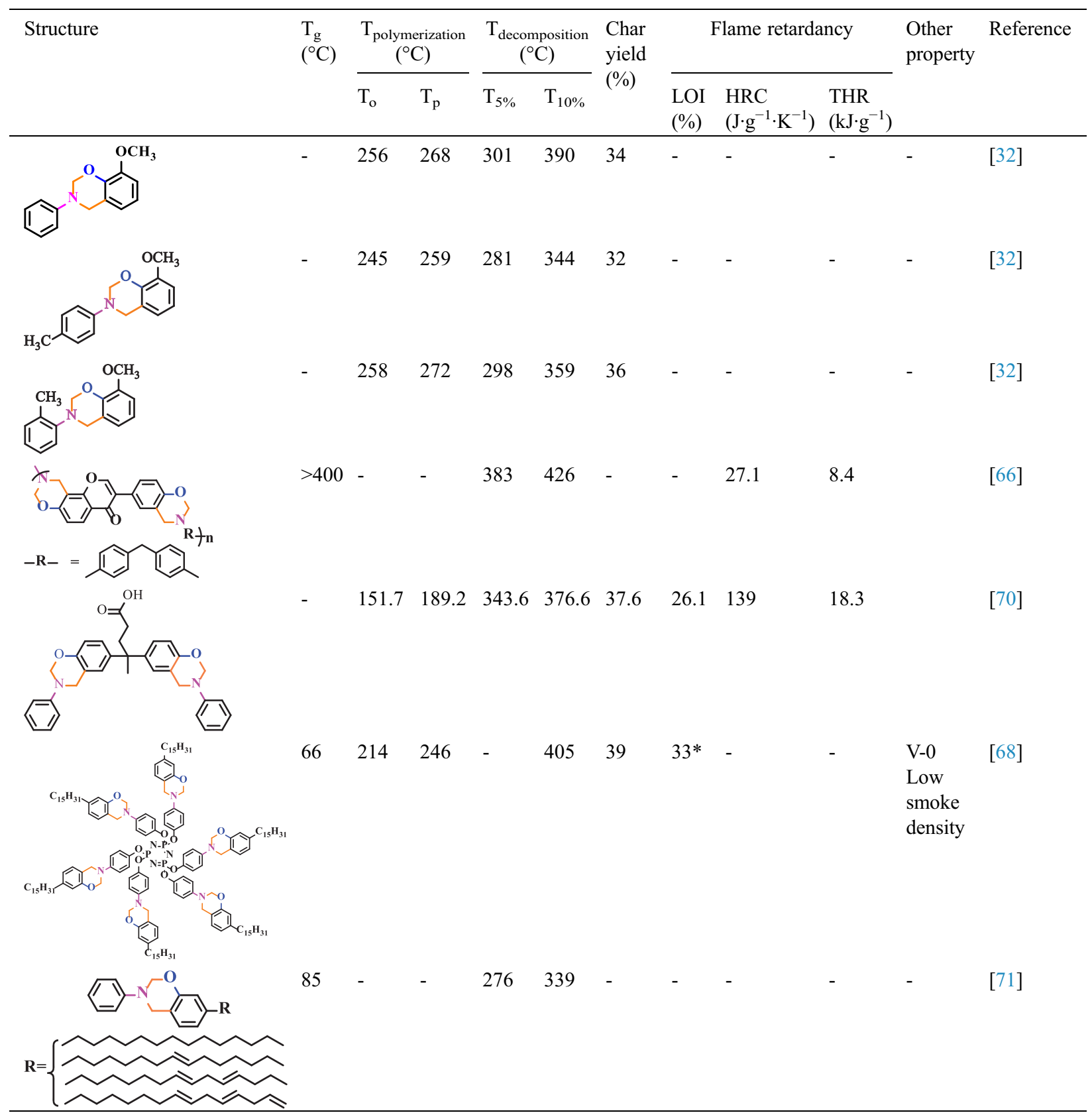

Note: $T_{g}$ value was reported from and DMA.

$\mathrm{T}_{5 \%}, \mathrm{~T}_{10 \%}$, and char yield was obtained from TGA in nitrogen.

LOI $=17.5+0.4 \times($ char yield, $\%)$. 


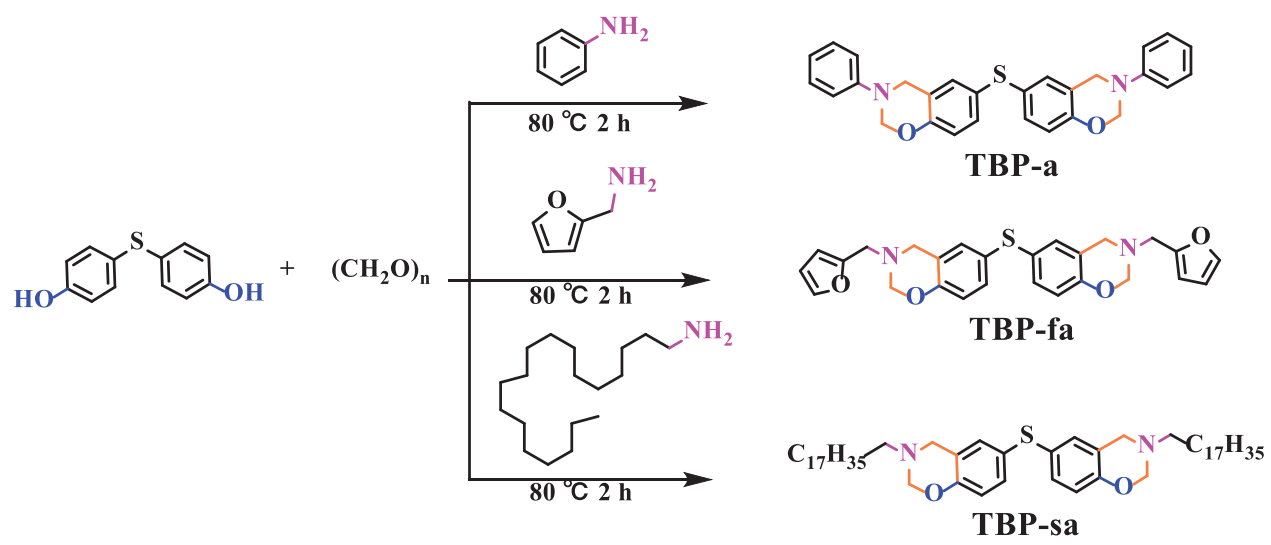

Figure 14: Synthesis of benzoxazine monomers based on 4, 4'-thiobisphenol

Flame retardancy. Flame retardancy is actually similar to thermal stability in some ways. If a system has outstanding thermal stability, pyrolysis reaction will be reduced during heating and less combustible component which served as fuel for combustion reaction will be released too, thus resulting in lower HRC and THR values. Zhang et al. [73]. successfully introduced the maleic anhydride group into benzoxazine monomers. In the process of thermal curing, $\mathrm{C}=\mathrm{C}$ bonds on the maleic anhydride group also participated in polymerization to form more complex cross-linking networks with higher cross-linking density. There was no doubt that poly(HPMI-a) exhibited remarkable thermal stability and flame retardancy with an HRC value of $33.4 \mathrm{~J} \cdot \mathrm{g}^{-1} \cdot \mathrm{K}^{-1}$ and a THR value of $7.0 \mathrm{~kJ} \cdot \mathrm{g}^{-1}$.

Water solubility. Common benzoxazine monomers, including many other polymer monomers, are hydrophobic and insoluble in water. But Dumas reported a novel benzoxazine monomer (A-Fa) synthesized from arbutin, a naturally occurring phenolic compound and furfurylamine [44]. The high hydroxyl content of the monomer makes it easy to dissolve in water, paving the way for more possible environmentally friendly applications, especially in paints, paints, and adhesives fields. Water can be used as a solvent to dissolve benzoxazine monomers and then prepare films on various substrates such as glass and aluminum. Once polymerization and cross-linking reaction happened, the coating is insoluble in water, which has potential use in preparing anticorrosion coatings, paintings, or adhesives.

Thermal and flame retardant properties of four typical benzoxazines derived from bio-based amines are summarized in Table 4 , including $\mathrm{T}_{\mathrm{g}}, \mathrm{T}_{\text {polymerization, }} \mathrm{T}_{\text {decomposition, }}$, char yield, flame retardancy, and some other properties. Furan ring structure can endow the system with high crosslinking density, which improves the thermal stability of the system with high decomposition temperature and char yield. But many of their properties are not as good as those of fully bio-based benzoxazines.

\subsection{Bio-Based Benzoxazine Thermosetting Composites}

The synthesized bio-based benzoxazine can also be doped into benzoxazine or other materials to prepare some high-performance modified materials. For example, the thermal stability and flame retardancy of the system can be effectively improved by adding a certain amount of bio-based benzoxazine monomers to petroleum-based benzoxazine and copolymerizing together. Similarly, when preparing composite materials, some other elements or matrices are introduced to further improve the properties of materials. The synthesized composites also possess other special properties, including outstanding flexibility [75], anti-corrosion performance, and selective absorption property $[69,76]$ rather than only thermal property. 
Table 4: Thermal characterization of four typical benzoxazines derived from bio-based amines and some other properties

\begin{tabular}{|c|c|c|c|c|c|c|c|c|c|c|}
\hline \multirow[t]{2}{*}{ Structure } & \multirow[t]{2}{*}{$\begin{array}{l}\mathrm{T}_{\mathrm{g}} \\
\left({ }^{\circ} \mathrm{C}\right)\end{array}$} & \multicolumn{2}{|c|}{$\begin{array}{c}\mathrm{T}_{\text {polymerization }} \\
\left({ }^{\circ} \mathrm{C}\right)\end{array}$} & \multicolumn{2}{|c|}{$\begin{array}{c}\mathrm{T}_{\text {decomposition }} \\
\left({ }^{\circ} \mathrm{C}\right)\end{array}$} & \multirow{2}{*}{$\begin{array}{l}\text { Char } \\
\text { yield } \\
(\%)\end{array}$} & \multicolumn{3}{|c|}{ Flame retardancy } & \multirow[t]{2}{*}{ Reference } \\
\hline & & $\mathrm{T}_{\mathrm{o}}$ & $\mathrm{T}_{\mathrm{p}}$ & $\mathrm{T}_{5 \%}$ & $\mathrm{~T}_{10 \%}$ & & $\begin{array}{l}\text { LOI } \\
(\%)\end{array}$ & $\begin{array}{l}\mathrm{HRC} \\
\left(\mathrm{J} \cdot \mathrm{g}^{-1} \cdot \mathrm{K}^{-1}\right)\end{array}$ & $\begin{array}{l}\text { THR } \\
\left(\mathrm{kJ} \cdot \mathrm{g}^{-1}\right)\end{array}$ & \\
\hline & & 222 & 230 & 388 & 437 & 68 & $45^{*}$ & 55.0 & 11.3 & [72] \\
\hline & 296 & - & 217 & 350 & 403 & 58 & - & 33.4 & 7.0 & [73] \\
\hline & 190 & - & 207 & - & - & - & - & - & - & [44] \\
\hline & - & 184 & 237 & 360 & 403 & 57 & 38 & - & - & [74] \\
\hline
\end{tabular}

Note: $\mathrm{T}_{\mathrm{g}}$ value was reported from DMA.

$\mathrm{T}_{5 \%}, \mathrm{~T}_{10 \%}$, and char yield was obtained from TGA in nitrogen.

LOI* $=17.5+0.4 *($ char yield, $\%)$.

The research focused on the composites modified by bio-based benzoxazine with silica, or introducing some silicon-containing groups like siloxane and POSS into composite material systems has gained a substantial amount of attention. POSS nanoparticles are dispersed homogeneously throughout the matrix, and composite materials possess low dielectric values and moisture absorption values, which broaden their application on microelectronics packaging [77]. Three kinds of POSS-benzoxazine composites and the synthesized process are presented in Fig. 15.

Peng et al. [76] chose a melamine sponge (MS) as raw material and fabricated a series of polybenzoxazine-modified MSs (PB-MSs). With the increasing benzoxazine content, PB-MSs showed higher water contact angle and excellent gravimetric absorption capacity, which could observe more than $60 \%$ retentive absorption capacity after 5 absorbing-squeezing cycles. The outstanding absorption selectivity showed great potential application in the field of environmental pollution treatment for effective oil/water separation.

Oliveira et al. [78] combined bio-based benzoxazine monomers with Manicaria saccifera fabrics to obtain bio-composites with satisfactory thermal and mechanical properties. The most important thing was that these composites were made with less than $40 \%$ of oil-based material, but obtaining good properties, especially flame retardancy.

Yang et al. [74] utilized chitosan, salicylaldehyde, and furfurylamine to prepare composite materials with regular surfaces and a more uniform pore, which gave it high adsorption capacity rather than introducing silicon-containing components. It can absorb $95 \%$ of rhodamine B in solution within $48 \mathrm{~h}$, indicating that it has a remarkable application prospect on oil/water separation. 


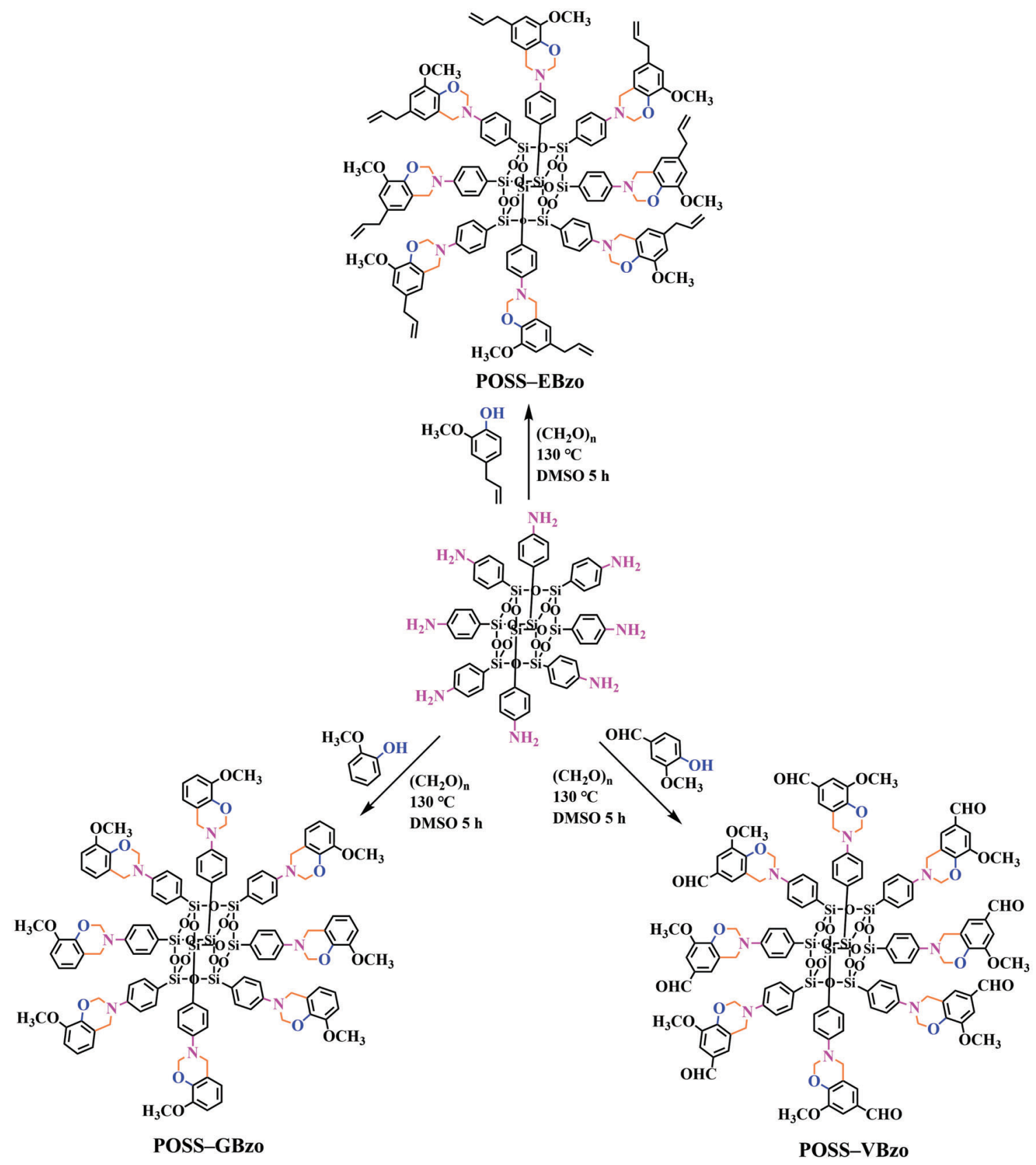

Figure 15: Synthesis of POSS-benzoxazine monomers

\section{Summary and Perspective}

There is no doubt that sustainable development and environmental protection have attracted more attention over the past decades. Bio-based benzoxazines made from natural renewable raw materials like eugenol, vanillin, daidzein, guaiacol have been widely explored and developed to replace petroleumbased benzoxazines. Similar to many synthetic polymer materials, bio-based benzoxazines also have some serious weaknesses of poor thermal stability and flammability. Thus, it is of great significance to synthesize bio-based benzoxazines with outstanding flame retardancy. Until now, bio-based benzoxazines have not been widely reported and the only reports are main about curing kinetics and thermal stability, 
indicating that the research of flame retardancy in this field is just beginning. Generally, the enhancement of flame retardancy can be designed by two approaches: (1) designing bio-based benzoxazine monomers with good thermal stability and high charring yield, curing alone or copolymerizing with petroleum-based benzoxazines or other materials to prepare composites (2) introducing elements such as phosphorus and silicon into the chemical structure or molecular chain of benzoxazine monomers.

It is still a challenge and limitation for scalable production due to the high cost of bio-based materials for the synthesis of bio-based benzoxazine monomers. Moreover, the flame retardant mechanism is not very clear, and thus it is necessary to clarify the flame retardant mechanism through more advanced characterization methods. Facing these challenges and problems, there is still a long way to go for the industrial production and large-scale application of bio-based benzoxazines. Considering the development trend in this field, the design of bio-based benzoxazine monomers with more unique properties and practical application prospects while maintaining excellent thermal stability and flame retardancy at the same time is an important development direction of this field in the future.

Funding Statement: We gratefully acknowledge financial support from the National Natural Science Foundation of China (Grant No. 22075265) and the Youth Innovation Promotion Association of the Chinese Academy of Sciences (Grant No. 2021459).

Conflicts of Interest: The authors declare that they have no conflicts of interest to report regarding the present study.

\section{References}

1. Ghosh, N. N., Kiskan, B., Yagci, Y. (2007). Polybenzoxazines-new high performance thermosetting resins: Synthesis and properties. Progress in Polymer Science, 32(11), 1344-1391. DOI 10.1016/j. progpolymsci.2007.07.002.

2. Agag, T., Liu, J., Graf, R., Spiess, H. W., Ishida, H. (2012). Benzoxazole resin: A novel class of thermoset polymer via smart benzoxazine resin. Macromolecules, 45(22), 8991-8997. DOI 10.1021/ma300924s.

3. Hao, B., Han, L., Liu, Y., Zhang, K. (2020). An apigenin-based bio-benzoxazine with three polymerizable functionalities: Sustainable synthesis, thermal latent polymerization, and excellent thermal properties of its thermosets. Polymer Chemistry, 11(36), 5800-5809. DOI 10.1039/D0PY00983K.

4. Ishida, H. (2011). Handbook of benzoxazine resins. UK: Elsevier.

5. Lyu, Y., Ishida, H. (2019). Natural-sourced benzoxazine resins, homopolymers, blends and composites: A review of their synthesis, manufacturing and applications. Progress in Polymer Science, 99, 101168. DOI 10.1016/j. progpolymsci.2019.101168.

6. Han, L., Salum, M. L., Zhang, K., Froimowicz, P., Ishida, H. (2017). Intrinsic self-initiating thermal ring-opening polymerization of 1, 3-benzoxazines without the influence of impurities using very high purity crystals. Journal of Polymer Science Part A-Polymer Chemistry, 55(20), 3434-3445. DOI 10.1002/pola.28723.

7. Deliballi, Z., Kiskan, B., Yagci, Y. (2018). Main-chain benzoxazine precursor block copolymers. Polymer Chemistry, 9(2), 178-183. DOI 10.1039/C7PY01873H.

8. Lligadas, G., Tuzun, A., Ronda, J. C., Galia, M., Cadiz, V. (2014). Polybenzoxazines: New players in the bio-based polymer arena. Polymer Chemistry, 5(23), 6636-6644. DOI 10.1039/c4py00914b.

9. Iguchi, D., Ohashi, S., Abarro, G., Yin, X., Winroth, S. et al. (2018). Development of hydrogen-rich benzoxazine resins with low polymerization temperature for space radiation shielding. ACS Omega, 3(9), 11569-11581. DOI 10.1021/acsomega.8b01297.

10. Liu, X., Ma, S., Jin, Z., Li, T. (2016). Research progress on bio-basedthermosetting resins. Polymer International, 65(2), 164-173. DOI 10.1002/pi.5027.

11. Hamed, Y. (2018). Ionic liquid modified lignin-phenol-glyoxal resin: A green alternative resin for production of particleboards. The Journal of Adhesion, 95(12), 1075-1087. DOI 10.1080/00218464.2018.1471994. 
12. Lü, Y., Pan, H., Yin, J. (2012). Removal of the polycyclic aromatic to produce eco-friendly aromatic-rich rubber extender oils. Petroleum Science and Technology, 30(13), 1335-1342. DOI 10.1080/10916466.2010.503218.

13. Vogel, S. A. (2012). Is it safe? BPA and the struggle to define the safety of chemicals. Berkeley: University of California Press. DOI 10.1525/9780520954205.

14. Oliveira, J. R., Kotzebue, L. R. V., Mazzetto, S. E., Lomonaco, D. (2019). Towards bio-based high-performance polybenzoxazines: Agro-wastes as starting materials for BPA-free thermosets via efficient microwave-assisted synthesis. European Polymer Journal, 116, 534-544. DOI 10.1016/j.eurpolymj.2019.04.014.

15. Wang, C., Sun, J., Liu, X., Sudo, A., Endo, T. (2012). Synthesis and copolymerization of fully bio-based benzoxazines from guaiacol, furfurylamine and stearylamine. Green Chemistry, 14(10), 2799-2806. DOI $10.1039 / \mathrm{c} 2 \mathrm{gc} 35796 \mathrm{~h}$.

16. Xu, H., Zhang, W., Lu, Z., Zhang, G. (2013). Hybrid polybenzoxazine with tunable properties. RSC Advances, 3(11), 3677-3682. DOI 10.1039/c3ra22247k.

17. Dumas, L., Bonnaud, L., Olivier, M., Poorteman, M., Dubois, P. (2015). Bio-based high performance thermosets: Stabilization and reinforcement of eugenol-based benzoxazine networks with BMI and CNT. European Polymer Journal, 67, 494-502. DOI 10.1016/j.eurpolymj.2014.11.030.

18. Krishnamoorthy, K., Subramani, D., Eeda, N., Muthukaruppan, A. (2019). Development and characterization of fully bio-based polybenzoxazine-silica hybrid composites for low-k and flame-retardant applications. Polymers for Advanced Technologies, 30(7), 1856-1864. DOI 10.1002/pat.4618.

19. Thirukumaran, P., Shakila, A., Muthusamy, S. (2014). Synthesis and characterization of novel bio-based benzoxazines from eugenol. RSC Advances, 4(16), 7959-7966. DOI 10.1039/c3ra46582a.

20. Yang, R., Han, M., Hao, B., Zhang, K. (2020). Biobased high-performance tri-furan functional bis-benzoxazine resin derived from renewable guaiacol, furfural and furfurylamine. European Polymer Journal, 131, 109706. DOI 10.1016/j.eurpolymj.2020.109706.

21. Liu, X., Zhang, R., Li, T., Zhu, P., Zhuang, Q. (2017). Novel fully biobased benzoxazines from rosin: Synthesis and properties. ACS Sustainable Chemistry \& Engineering, 5(11), 10682-10692. DOI 10.1021/ acssuschemeng.7b02650.

22. Singh, D. D., Sharma, P., Nebhani, L. (2020). Tuning the architecture and performance of multifarious benzoxazine resin based on guaiacol and polyethylenimine. European Polymer Journal, 134, 109848. DOI 10.1016/j.eurpolymj.2020.109848.

23. Liu, Y., Cao, L., Luo, J., Peng, Y., Ji, Q. et al. (2018). Biobased nitrogen- and oxygen-codoped carbon materials for high-performance supercapacitor. ACS Sustainable Chemistry \& Engineering, 7(2), 2763-2773. DOI 10.1021/ acssuschemeng.8b05947.

24. Periyasamy, T., Asrafali, S. P., Kim, S. C. (2020). Investigating the effects of amine-functionalized carbon balls in a polybenzoxazine matrix. New Journal of Chemistry, 44(28), 12384-12396. DOI 10.1039/D0NJ00698J.

25. Agag, T., An, S. Y., Ishida, H. (2013). 1, 3-bis(benzoxazine) from cashew nut shell oil and diaminodiphenyl methane and its composites with wood flour. Journal of Applied Polymer Science, 127(4), 2710-2714. DOI 10.1002/app.37584.

26. Cao, Y., Chen, C., Lu, X., Xu, D., Huang, J. et al. (2021). Bio-based polybenzoxazine superhydrophobic coating with active corrosion resistance for carbon steel protection. Surface and Coatings Technology, 405, 126569. DOI 10.1016/j.surfcoat.2020.126569.

27. Shukla, S., Mahata, A., Pathak, B., Lochab, B. (2015). Cardanol benzoxazines-interplay of oxazine functionality (mono to tetra) and properties. RSC Advances, 5(95), 78071-78080. DOI 10.1039/c5ra14214h.

28. Zhang, K., Han, M., Liu, Y., Froimowicz, P. (2019). Design and synthesis of bio-based high-performance trioxazine benzoxazine resin via natural renewable resources. ACS Sustainable Chemistry \& Engineering, 7(10), 9399-9407. DOI 10.1021/acssuschemeng.9b00603.

29. Dogan, Y. E., Satilmis, B., Uyar, T. (2019). Synthesis and characterization of bio-based benzoxazines derived from thymol. Journal of Applied Polymer Science, 136(17), 47371. DOI 10.1002/app.47371. 
30. Teng, N., Yang, S., Dai, J., Wang, S., Zhao, J. et al. (2019). Making benzoxazine greener and stronger: Renewable resource, microwave irradiation, green solvent, and excellent thermal properties. ACS Sustainable Chemistry \& Engineering, 7(9), 8715-8723. DOI 10.1021/acssuschemeng.9b00607.

31. Dumas, L., Bonnaud, L., Olivier, M., Poorteman, M., Dubois, P. (2016). Chavicol benzoxazine: Ultrahigh Tg biobased thermoset with tunable extended network. European Polymer Journal, 81, 337-346. DOI 10.1016/j. eurpolymj.2016.06.018.

32. Oliveira, J. R., Kotzebue, L. R. V., Ribeiro, F. W. M., Mota, B. C., Zampieri, D. et al. (2017). Microwave-assisted solvent-free synthesis of novel benzoxazines: A faster and environmentally friendly route to the development of bio-based thermosetting resins. Journal of Polymer Science Part A: Polymer Chemistry, 55(21), 3534-3544. DOI 10.1002/pola.28755.

33. Wang, Y. N., Niu, X., Xing, X., Wang, S., Jing, X. (2017). Curing behaviour and properties of a novel benzoxazine resin via catalysis of 2-phenyl-1, 3, 2-benzodioxaborole. Reactive and Functional Polymers, 117, 60-69. DOI 10.1016/j.reactfunctpolym.2017.06.004.

34. Sun, J. Q., Wei, W., Xu, Y. Z., Qu, J. H., Liu, X. et al. (2015). A curing system of benzoxazine with amine: Reactivity, reaction mechanism and material properties. RSC Advances, 5(25), 19048-19057. 10.1039/ c4ra16582a.

35. Yue, J., Zhao, C., Dai, Y., Li, H., Li, Y. (2017). Catalytic effect of exfoliated zirconium phosphate on the curing behavior of benzoxazine. Thermochimica Acta, 650, 18-25. DOI 10.1016/j.tca.2017.01.005.

36. Qi, S., Wang, H., Han, G., Yang, Z., Zhang, X. A. et al. (2016). Synthesis, characterization, and curing behavior of carborane-containing benzoxazine resins with excellent thermal and thermo-oxidative stability. Journal of Applied Polymer Science, 133(23), 43488. DOI 10.1002/app.43488.

37. Wang, Y. X., Ishida, H. (1999). Cationic ring-opening polymerization of benzoxazines. Polymer, 40(16), 45634570. DOI 10.1016/s0032-3861(99)00074-9.

38. Lin, C. M., Chen, C. H., Lin, C. H., Juang, T. Y. (2018). High-performance bio-based benzoxazines derived from phosphinated biphenols and furfurylamine. European Polymer Journal, 108 48-56. DOI 10.1016/j. eurpolymj.2018.08.024.

39. Huang, J. M., Kuo, S. W., Chen, J. K., Chang, F. C. (2005). Synthesis and characterizations of a vinyl-terminated benzoxazine monomer and its blending with polyhedral oligomeric silsesquioxane (POSS). Polymer, 46(7), 23202330. DOI 10.1016/j.polymer.2005.01.025.

40. Ishida, H., Chiou, K. (2013). Incorporation of natural renewable components and waste byproducts to benzoxazine based high performance materials. Current Organic Chemistry, 17(9), 913-925. DOI 10.2174/ 1385272811317090005.

41. Zhang, K., Liu, Y., Han, M., Froimowicz, P. (2020). Smart and sustainable design of latent catalyst-containing benzoxazine-bio-resins and application studies. Green Chemistry, 22(4), 1209-1219. DOI 10.1039/c9gc03504d.

42. Zhang, L., Zhu, Y., Li, D., Wang, M., Chen, H. et al. (2015). Preparation and characterization of fully renewable polybenzoxazines from monomers containing multi-oxazine rings. RSC Advances, 5(117), 96879-96887. DOI 10.1039/c5ra17164d.

43. Sharma, P., Dutta, P., Nebhani, L. (2019). Sustainable approach towards enhancing thermal stability of bio-based polybenzoxazines. Polymer, 184, 121905. DOI 10.1016/j.polymer.2019.121905.

44. Dumas, L., Bonnaud, L., Olivier, M., Poorteman, M., Dubois, P. (2016). Arbutin-based benzoxazine: En route to an intrinsic water soluble biobased resin. Green Chemistry, 18(18), 4954-4960. DOI 10.1039/c6gc01229a.

45. Kotzebue, L. R. V., de Oliveira, J. R., da Silva, J. B., Mazzetto, S. E., Ishida, H. et al. (2018). Development of fully biobased high-performance bis-benzoxazine under environmentally friendly conditions. ACS Sustainable Chemistry \& Engineering, 6(4), 5485-5494. DOI 10.1021/acssuschemeng.8b00340.

46. Ohashi, S. (2017). Systematic studies of substituent effect on benzoxazines and application in its polymer form. (Ph.D. Thesis). Department of Macromolecular Science and Engineering, Case Western Reserve University, USA.

47. Ren, S., Miao, X., Zhao, W., Zhang, S., Wang, W. (2019). A fully bio-based benzoxazine as latent catalyst for bisphenol a/aniline-based benzoxazine. Materials Today Communications, 20, 100568. DOI 10.1016/j. mtcomm.2019.100568. 
48. Zhang, W., Froimowicz, P., Arza, C. R., Ohashi, S., Xin, Z. et al. (2016). Latent catalyst-containing naphthoxazine: Synthesis and effects on ring-opening polymerization. Macromolecules, 49(19), 7129-7140. DOI 10.1021/acs. macromol.6b01177.

49. Lin, R. H., Zhu, Y. F., Zhang, Y. J., Wang, L. M., Yu, S. J. (2018). Pyrogallol-based benzoxazines with latent catalytic characteristics: The temperature-dependent effect of hydrogen bonds on ring-opening polymerization. European Polymer Journal, 102, 141-150. DOI 10.1016/j.eurpolymj.2018.03.015.

50. Li, X., Yao, H., Lu, X., Chen, C., Cao, Y. et al. (2020). Effect of pyrogallol on the ring-opening polymerization and curing kinetics of a fully bio-based benzoxazine. Thermochimica Acta, 694, 178787. DOI 10.1016/j. tca.2020.178787.

51. Kirubakaran, R., Sharma, P., Manisekaran, A., Bijwe, J., Nebhani, L. (2020). Phloretic acid: A smart choice to develop low-temperature polymerizable bio-based benzoxazine thermosets. Journal of Thermal Analysis and Calorimetry, 142(3), 1233-1242. DOI 10.1007/s10973-019-09228-y.

52. Andreu, R., Reina, J. A., Ronda, J. C. (2008). Carboxylic acid-containing benzoxazines as efficient catalysts in the thermal polymerization of benzoxazines. Journal of Polymer Science Part A: Polymer Chemistry, 46(18), 60916101. DOI 10.1002/pola.22921.

53. Zhan, Z. M., Yan, H. Q., Yin, P., Cheng, J., Fang, Z. P. (2019). Synthesis and properties of a novel bio-based benzoxazine resin with excellent low-temperature curing ability. Polymer International, 69(4), 355-362. DOI 10.1002/pi.5957.

54. Ganfoud, R., Guigo, N., Puchot, L., Verge, P., Sbirrazzuoli, N. (2019). Investigation on the role of the alkyl side chain of cardanol on benzoxazine polymerization and polymer properties. European Polymer Journal, 119, 120 129. DOI 10.1016/j.eurpolymj.2019.07.026.

55. Pereira, R. C. S., Kotzebue, L. R. V., Zampieri, D., Mele, G., Mazzetto, S. E. et al. (2019). Influence of natural substituents in the polymerization behavior of novel bio-based benzoxazines. Materials Today Communications, 21, 100629. DOI 10.1016/j.mtcomm.2019.100629.

56. Zhang, Y., Liu, X., Zhan, G., Zhuang, Q., Zhang, R. et al. (2019). Study on the synergistic anticorrosion property of a fully bio-based polybenzoxazine copolymer resin. European Polymer Journal, 119, 477-486. DOI 10.1016/j. eurpolymj.2019.07.020.

57. Thirukumaran, P., Shakila Parveen, A., Sarojadevi, M. (2014). Synthesis and copolymerization of fully biobased benzoxazines from renewable resources. ACS Sustainable Chemistry \& Engineering, 2(12), 2790-2801. DOI $10.1021 / \mathrm{sc} 500548 \mathrm{c}$.

58. Zhan, Z., Yan, H., Wang, H., Cheng, J., Ran, S. et al. (2020). Novel full bio-based phloroglucinol benzoxazine resin: Synthesis, curing reaction and thermal stability. Polymer, 200, 122534. DOI 10.1016/j. polymer.2020.122534.

59. Guo, W. W., Wang, X., Gangireddy, C. S. R., Wang, J. L., Pan, Y. et al. (2019). Cardanol derived benzoxazine in combination with boron-doped graphene toward simultaneously improved toughening and flame retardant epoxy composites. Composites Part A-Applied Science and Manufacturing, 116, 13-23. DOI 10.1016/j. compositesa.2018.10.010.

60. Dai, J., Teng, N., Shen, X., Liu, Y., Cao, L. et al. (2018). Synthesis of biobased benzoxazines suitable for vacuumassisted resin transfer molding process via introduction of soft silicon segment. Industrial \& Engineering Chemistry Research, 57(8), 3091-3102. DOI 10.1021/acs.iecr.7b04716.

61. Devaraju, S., Krishnadevi, K., Sriharshitha, S., Alagar, M. (2018). Design and development of environmentally friendly polybenzoxazine-silica hybrid from renewable bio-resource. Journal of Polymers and the Environment, 27(1), 141-147. DOI 10.1007/s10924-018-1327-z.

62. Lu, G., Dai, J., Liu, J., Tian, S., Xu, Y. et al. (2020). A new sight into bio-based polybenzoxazine: From tunable thermal and mechanical properties to excellent marine antifouling performance. ACS Omega, 5(7), 3763-3773. DOI 10.1021/acsomega.0c00025.

63. Sini, N. K., Bijwe, J., Varma, I. K. (2014). Renewable benzoxazine monomer from vanillin: Synthesis, characterization, and studies on curing behavior. Journal of Polymer Science Part A: Polymer Chemistry, 52(1), 7-11. DOI 10.1002/pola.26981. 
64. Froimowicz, P. C. R. A., Han, L., Ishida, H. (2016). Smart, sustainable, and ecofriendly chemical design of fully bio-based thermally stable thermosets based on benzoxazine chemistry. ChemSusChem, 9(15), 1921-1928. DOI $10.1002 /$ cssc. 201600968.

65. Feng, Z., Zeng, M., Meng, D., Chen, J., Zhu, W. et al. (2020). A novel bio-based benzoxazine resin with outstanding thermal and superhigh-frequency dielectric properties. Journal of Materials Science: Materials in Electronics, 31(5), 4364-4376. DOI 10.1007/s10854-020-02995-7.

66. Han, M., You, S., Wang, Y., Zhang, K., Yang, S. (2019). Synthesis of highly thermally stable daidzein-based mainchain-type benzoxazine resins. Polymers, 11(8), 1341. DOI 10.3390/polym11081341.

67. Wang, X., Niu, H., Huang, J., Song, L., Hu, Y. (2021). A desoxyanisoin- and furfurylamine-derived highperformance benzoxazine thermoset with high glass transition temperature and excellent anti-flammability. Polymer Degradation and Stability, 189, 109604. DOI 10.1016/j.polymdegradstab.2021.109604.

68. Amarnath, N., Appavoo, D., Lochab, B. (2017). Eco-friendly halogen-free flame retardant cardanol polyphosphazene polybenzoxazine networks. ACS Sustainable Chemistry \& Engineering, 6(1), 389-402. DOI 10.1021/acssuschemeng.7b02657.

69. Yao, H., Lu, X., Xin, Z., Zhang, H., Li, X. (2019). A durable bio-based polybenzoxazine/ $\mathrm{SiO}_{2}$ modified fabric with superhydrophobicity and superoleophilicity for oil/water separation. Separation and Purification Technology, 229, 115792. DOI 10.1016/j.seppur.2019.115792.

70. Yan, H., Sun, C., Fang, Z., Liu, X., Zhu, J. et al. (2016). Synthesis of an intrinsically flame retardant bio-based benzoxazine resin. Polymer, 97(1), 418-427. DOI 10.1016/j.polymer.2016.05.053.

71. Ribeiro, F. W. M., Kotzebue, L. R. V., Oliveira, J. R., Maia, F. J. N., Mazzetto, S. E. et al. (2017). Thermal and mechanical analyses of biocomposites from cardanol-based polybenzoxazine and bamboo fibers. Journal of Thermal Analysis and Calorimetry, 129(1), 281-289. DOI 10.1007/s10973-017-6191-x.

72. Lyu, Y., Zhang, Y., Ishida, H. (2020). Intrinsically noncombustible polymers without flame retardant additives: Sulfur-containing and bio-based benzoxazines. European Polymer Journal, 133(15), 109770. DOI 10.1016/j. eurpolymj.2020.109770.

73. Zhang, K., Liu, Y., Ishida, H. (2019). Polymerization of an AB-type benzoxazine monomer toward different polybenzoxazine networks: When Diels-Alder reaction meets benzoxazine chemistry in a single-component resin. Macromolecules, 52(19), 7386-7395. DOI 10.1021/acs.macromol.9b01581.

74. Yang, Y., Li, R., Liu, X., Ma, Q., Zhang, Y. et al. (2021). Chitosan/biological benzoxazine composites: Effect of benzoxazine structure on the properties of composites. Reactive and Functional Polymers, 164, 104931. DOI 10.1016/j.reactfunctpolym.2021.104931.

75. Li, S., Zou, T., Feng, L., Liu, X., Tao, M. (2013). Preparation and properties of cardanol-based polybenzoxazine/ $\mathrm{SiO}_{2}$ hybrids by sol-gel technique. Journal of Applied Polymer Science, 128(6), 4164-4171. DOI 10.1002/ app.38607.

76. Peng, Y., Dai, J., Liu, Y., Cao, L., Zhu, J. et al. (2019). Bio-based polybenzoxazine modified melamine sponges for selective absorption of organic solvent in water. Advanced Sustainable Systems, 3(3), 1800126. DOI 10.1002/ adsu.201800126.

77. Periyasamy, T., Asrafali, S. P., Muthusamy, S. (2015). New benzoxazines containing polyhedral oligomeric silsesquioxane from eugenol, guaiacol and vanillin. New Journal of Chemistry, 39(3), 1691-1702. DOI 10.1039/C4NJ02047B.

78. Oliveira, J. R., Kotzebue, L. R. V., Freitas, D. B., Mattos, A. L. A., da Costa Júnior, A. E. et al. (2020). Towards novel high-performance bio-composites: Polybenzoxazine-based matrix reinforced with manicaria saccifera fabrics. Composites Part B: Engineering, 194, 108060. DOI 10.1016/j.compositesb.2020.108060. 